\title{
The biology and targeting of FLT3 in pediatric leukemia
}

\section{Colleen E. Annesley and Patrick Brown*}

Oncology and Pediatrics, The Sidney Kimmel Comprehensive Cancer Center, Johns Hopkins University School of Medicine, Baltimore, MD, USA

\section{Edited by:}

Alan Wayne, Children's Hospital Los Angeles, USA

Reviewed by:

Sarah K. Tasian, The Children's Hospital of Philadelphia, USA;

University of Pennsylvania School of Medicine, USA

Michael James Burke, Medical

College of Wisconsin, USA

\section{*Correspondence:}

Patrick Brown, Oncology and Pediatrics, The Sidney Kimmel Comprehensive Cancer Center, Johns Hopkins University School of Medicine, 1650 Orleans Street, CRB-I 2M46, Baltimore, MD 21231, USA e-mail:pbrown2@jhmi.edu

\begin{abstract}
Despite remarkable improvement in treatment outcomes in pediatric leukemia over the past several decades, the prognosis for high-risk groups of acute myeloid leukemia (AML) and acute lymphoblastic leukemia (ALL), as well as for relapsed leukemia, remains poor. Intensification of chemotherapy regimens for those at highest risk has improved success rates, but at the cost of significantly increased morbidity and long-term adverse effects. With the success of imatinib in Philadelphia-chromosome-positive leukemia and all-trans retinoic acid in acute promyelocytic leukemia, the quest to find additional molecularly targeted therapies has generated much excitement over recent years. Another such possible target in pediatric acute leukemia is FMS-like tyrosine kinase 3 (FLT3). FLT3 aberrations are among the most frequently identified transforming events in $A M L$, and have significant clinical implications in both high-risk pediatric $A M L$ and in certain high-risk groups of pediatric ALL. Therefore, the successful targeting of FLT3 has tremendous potential to improve outcomes in these subsets of patients. This article will give an overview of the molecular function and signaling of the FLT3 receptor, as well as its pathogenic role in leukemia. We review the discovery of targeting FLT3, discuss currently available FLT3 inhibitors in pediatric leukemia and results of clinical trials to date, and finally, consider the future promise and challenges of FLT3 inhibitor therapy.
\end{abstract}

Keywords: FLT3, FLT3 inhibitor, MLLr, MLL, tyrosine kinase inhibitors

\section{INTRODUCTION}

Remarkable strides have been made in the past several decades in the treatment success rates of childhood acute lymphoblastic leukemia (ALL), with 5-year survival rates now approaching $90 \%$ (1). However, up to $20 \%$ of children will be refractory to treatment, or relapse following treatment, and the event-free survival (EFS) rate for these patients remains poor. In acute myeloid leukemia (AML), although the majority of children will achieve an initial remission with conventional chemotherapy, $<60 \%$ will be long-term survivors (2). Furthermore, the intensification of treatment regimens required to achieve the highest possible survival rates for poor risk leukemia has been pushed to the limit of tolerance, highlighting the need for effective targeted therapies (3).

Two successful examples of targeted therapies in pediatric leukemia include tyrosine kinase inhibitors in BCR-ABL-positive ALL (4) and all-trans retinoic acid (ATRA) in acute promyelocytic leukemia (APML) with the PML-RAR $\alpha$ fusion (5). FMS-like tyrosine kinase 3 (FLT3) represents another attractive target, given its overexpression on the majority of leukemia cells and the high rate of FLT3 mutations in human leukemia. Since the receptor was first described over 20 years ago, targeting FLT3 therapeutically has generated much excitement. The first clinical trials with FLT3 inhibitors took place 10 years ago, and though some inhibitors have shown good promise in effective targeting, they also presented several clinical challenges. This is underscored by the fact that no FLT3 inhibitors have been FDA-approved for the treatment of leukemia to date. This review will summarize the biology of FLT3 in leukemia, and discuss the benefits and hindrances associated with FLT3 inhibitor therapy.

\section{BIOLOGY OF THE FLT3 RECEPTOR}

\section{MOLECULAR STRUCTURE AND NORMAL TISSUE EXPRESSION OF FLT3}

FMS-like tyrosine kinase 3 belongs to the class III receptor tyrosine kinase (RTK) family, along with KIT, FMS, and platelet-derived growth factor receptor (PDGFR). As such, FLT3 contains an extracellular domain made up of five immunoglobulin-like regions at the amino terminus, a single transmembrane region, an intracellular juxtamembrane domain (JMD), and two kinase domains at the carboxyl terminus, separated by a kinase insert region $(6,7)$ (Figure 1). FLT3 is expressed in normal human bone marrow (BM), particularly in $\mathrm{CD} 34^{+}$hematopoietic stem and early progenitor cells $(6,8)$ and in dendritic cell progenitors (9). FLT3 is also expressed in human brain, placenta, and testis $(7,10)$, though its function in these tissues remains unclear.

\section{NORMAL RECEPTOR FUNCTION}

FMS-like tyrosine kinase 3 signaling is central to the development of hematopoietic stem cells, B-cell progenitors, dendritic cell progenitors, and natural killer (NK) cells. This was first demonstrated through studying the targeted disruption of either FLT3 or its ligand, FLT3 ligand (FL), in CD34 $4^{+}$cells or in mice $(8$, 11, 12). Mice homozygous for a deletion of FLT3 mature into normal adults, but BM evaluation reveals deficiencies in B-cell progenitors, and transplantation studies show deficiencies in Tlymphocytes and myeloid cells (11). In colony-forming assays, human $\mathrm{CD} 34^{+} \mathrm{FLT}^{\text {high }} \mathrm{BM}$ cells give rise to colony-forming unit granulocyte-monocyte (CFU-GM) colonies and are predominantly in G1 phase of cell cycle, whereas $\mathrm{CD} 34^{+}{ }^{+} \mathrm{FLT} 3^{\text {low }}$ cells give rise to erythroid colonies and are predominantly in G0 phase (13). Together, these data reveal the significant role of 


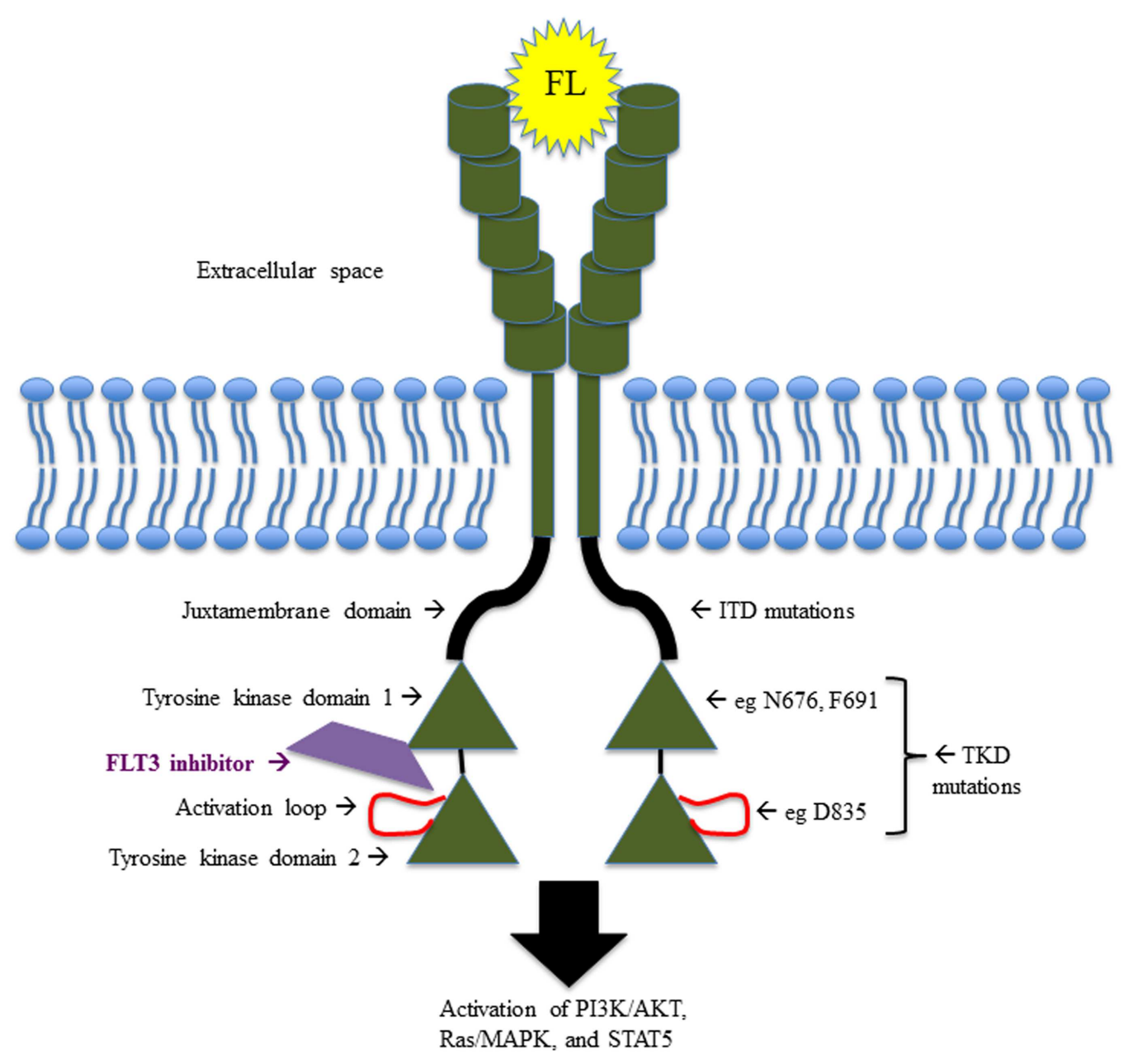

FIGURE 1 | Schematic illustrating the structure and function of FLT3, including the sites of the most common activating mutations

FLT3 in both differentiation and proliferation of hematopoietic progenitor cells.

\section{FLT3 ligand}

FMS-like tyrosine kinase 3 ligand was described shortly after the discovery of the FLT3 receptor $(14,15)$. FL is expressed in many different human tissues, though its co-expression with FLT3 is limited to the gonads and hematopoietic tissue (16). FL is also produced by BM stroma, an important source of cytokines and growth factors responsible for the proliferation and differentiation of hematopoietic progenitor cells (17). It is found in both soluble and membrane-bound forms, and selectively stimulates the proliferation and colony formation of $\mathrm{CD} 34^{+}$progenitor cells (16). Upon binding to FLT3, FL induces dimerization of the receptor and auto-phosphorylation of tyrosine residues in the kinase domains, leading to downstream activation and phosphorylation of protein substrates (18).

\section{FLT3 signaling pathways}

Upon stimulation with FL, FLT3 activation results in the downstream activation of multiple signaling pathways, including the
Ras/Raf and the phosphatidylinositol 3' kinase (PI3K) pathways. Many important signaling and adaptor proteins are involved, including signal transducer and activator of transcription 5 (STAT5), phospholipase C $\gamma$ (PLC- $\gamma)$, CBL, growth factor receptorbound protein 2 (Grb2), SHC, Src-homology 2 containing protein tyrosine phosphate (SHP-2), Src-homology 2 containing inositol phosphatase (SHIP), mitogen activated protein kinase (MAPK), and extracellular-signal regulated kinase (ERK1/2) (1924). This cascade of phosphorylation and activation ultimately results in increased cell proliferation, decreased cell apoptosis, and inhibition of cell differentiation.

\section{FLT3 ABERRANCIES IN LEUKEMIA}

FMS-like tyrosine kinase 3 is aberrantly expressed in all precursor B-cell (pre-B) ALL and nearly all AML primary leukemia samples, as well as a fraction of T-cell ALL patient samples $(25,26)$. FLT3 is also expressed in the majority of pre-B ALL and AML cell lines (27-29). FLT3 is expressed in most chronic myeloid leukemia (CML) blast crisis patient samples, irrespective of phenotype, as well as in several chronic lymphocytic leukemia (CLL) samples 
(26). Importantly, FLT3 is expressed on leukemia blasts regardless of CD34 expression, whereas FLT3 expression is limited to the $\mathrm{CD}^{+}{ }^{+}$population in normal human $\mathrm{BM}(26,27)$. This pattern of FLT3 expression in leukemia is in contrast to KIT and FMS expression, which are typically restricted to myeloid leukemia (25). FL is expressed in most leukemia cell lines from all cell lineages, and in one study, 40 of 110 human leukemia cell lines expressed both FL and FLT3 (27). Another study showed that wild-type FLT3 is constitutively activated in two-thirds of AML patient samples and in 4 of 13 leukemia cell lines tested (30). These cells co-expressed FLT3 and FL, suggesting a role for autocrine signaling.

\section{FLT3-ACTIVATING MUTATIONS}

Activating mutations of FLT3 were first described in AML in 1996. There are two broad categories: internal tandem duplications (ITD) and point mutations in the tyrosine kinase domain (TKD). In pediatric AML, activating mutations occur in 20$25 \%$ of patients, with roughly two-thirds of these harboring ITD mutations, and the remaining one-third with TKD point mutations.

\section{ITD mutations}

Internal tandem duplications mutations in the JMD of the FLT3 gene were first described in adult patients with AML, and even in that small cohort of patients, it appeared that these mutations conferred a poor prognosis (31). A region of the JMD coding sequence is replicated in a direct head-to-tail orientation, creating the ITD. As initially described, ITDs vary in length and location, but tend to occur in replicates of three nucleotides, maintaining an intact reading frame and not affecting other regions of the gene, including the kinase domains (31-33). ITD mutations result in ligand-independent dimerization of the FLT3 receptor, constitutive phosphorylation, and activation of the kinase domains (32, 34, 35). It is proposed that ITD mutations occur as DNA replication errors, and are selected due to the resulting growth advantage (32).

In both AML and normal hematopoiesis, self-renewal capacity is limited to the immature $\mathrm{CD} 34^{+} \mathrm{CD} 38^{-}$cell population (36). There is increasing evidence that FLT3-ITD has activity in hematopoietic stem cells (37), as demonstrated by the presence of ITD in the $\mathrm{CD} 34^{+} \mathrm{CD} 38^{-}$leukemia-initiating cell (LIC) population, and confirmation of the ITD mutation in these successfully engrafted LICs in a murine transplant model (38). In BM cells from a knock-in heterozygous FLT3-ITD-mutant mouse model, FLT3 expression and signaling was present within the long-term hematopoietic stem cell (LT-HSC) compartment, and importantly, the ITD mutation conferred a proliferative effect on this normally quiescent population, depleting the LT-HSC compartment (39). Interestingly, this effect was reversed with the FLT3 inhibitor sorafenib, repleting the LT-HSC population and returning these cells to a quiescent state.

Clinical relevance of ITD mutations in human leukemia. Internal tandem duplications mutations are a common somatic mutation in adult AML, occurring in approximately $20-35 \%$ of patients $(31,40-43)$. ITD mutations occur less frequently in pediatric AML, found in approximately 5-15\% of newly diagnosed patients (4446). The presence of an FLT3-ITD mutation in pediatric AML is associated with higher WBC counts at presentation, older age, higher rates of induction failure, and significantly worse survival. In a retrospective study of de novo AML pediatric patients enrolled in Children's Cancer Group study (CCG)-2891, multivariate analysis identified ITD mutations as an independent prognostic factor for poor outcome in pediatric AML. This study revealed 8-year overall survival (OS) and EFS rates of 13 and 7\%, respectively, for children with ITD mutations versus OS of $50 \%$ and EFS of $44 \%$ for children without ITD mutations (46). Following these results, the risk stratification of pediatric patients with ITD mutations has been a dynamic process. One pediatric study showed that the presence of FLT3-ITD mutations in the more primitive $\mathrm{CD} 34^{+} \mathrm{CD} 33^{-}$cell population was heterogeneous (present in approximately $80 \%$ of ITD-positive AML patients), and conferred a worse prognosis compared to patients in which the ITD mutations was only present in $\mathrm{CD} 34^{+} \mathrm{CD} 33^{+}$cells (47).

Furthermore, in a large retrospective study of adults with AML characterizing patients with FLT3 mutations, adults with higher ITD allelic ratios had significantly shorter overall and disease-free survival (42). A subsequent retrospective study of children with de novo AML, enrolled on studies CCG-2941 and -2961, determined that an ITD allelic ratio of 0.4 or higher identified the highest risk group with the worse prognosis, whereas children with allelic ratios $<0.4$ had similar outcomes as children with wild-type FLT3 (48). Therefore, the current Children's Oncology Group (COG) phase 3 clinical trial for AML risk-stratifies patients with FLT3-ITD allelic ratios $>0.4$ into the high-risk group, regardless of having any other low risk factor. These patients will receive more intensive chemotherapy, including the FLT3 inhibitor sorafenib (further discussed below), as well as hematopoietic stem cell transplantation (HSCT) in first remission, in an attempt to improve outcomes for this subset of patients.

Additionally, loss of the FLT3-wild-type allele and resultant copy number-neutral ITD homozygosity has been demonstrated in AML, particularly at disease progression, and is associated with a worse prognosis (49-51). Copy-neutral loss of heterozygosity $(\mathrm{CN}-\mathrm{LOH})$ is a common event in both solid and hematologic malignancies, and can lead to either inactivation of a tumor suppressor gene or enhanced activity of an oncogene. Acquired CN-LOH or uniparental disomy, is seen in leukemia with loss of the normal allele and duplication of the mutant allele (52-55), such as seen with FLT3-ITD mutations.

Although ITD mutations were first described in the JMD, it was later discovered that ITD mutations occur up to $30 \%$ of the time in non-JMD regions of the gene $(56,57)$. In fact, in a large review of 241 FLT3-ITD AML patients, those with an ITD in the beta-1 sheet of the TKD had a significantly inferior remission rate, relapse free survival, and OS compared to those with an ITD located in the JMD (57). This suggests relevance to identifying not only the presence and allelic burden of FLT3-ITD but also the ITD location.

There are conflicting reports as to whether the length of the ITD carries prognostic significance in AML. In one retrospective review of adult data, patients harboring an ITD $>40$ base pairs had an inferior 5-year OS of $13 \%$ compared to $26 \%$ in those with an ITD $<40$ base pairs, and $21 \%$ in patient with no ITD mutation (58). This group hypothesized that longer ITDs may lead to increased disruption of the auto-inhibitory function of the JMD. 
However, another group demonstrated opposing results, showing inferior survival in patients with shorter ITDs, using a cutoff of 70 base pairs (59). Prospective, larger studies are likely needed to determine whether ITD size truly affects prognosis.

Finally, a recent report evaluated the prevalence and prognostic significance of FLT3 mutations in childhood APML. It is well known that FLT3 mutations are common in APML, and the block in differentiation conferred by $\mathrm{t}(15 ; 17)$ likely cooperates with the proliferative advantage of FLT3 mutations. In 104 pediatric APML patients, $40 \%$ had either FLT3-ITD or a TKD point mutation. These patients had higher WBC counts at diagnosis and increased rates of induction deaths when treated with ATRA alone (60). No difference in outcomes with FLT3 mutations were demonstrated post-induction therapy. It is unclear if the increased induction deaths were due to the higher WBC count or FLT3 mutations; however, it is hypothesized that the presence of a FLT3 mutation is causative of the higher WBC counts in these patients. Geneexpression profiling in FLT3-mutant APML showed up-regulation of genes involved in proliferation, coagulation, and inflammation (61). This suggests a role for evaluating FLT3 mutation status in APML and consideration of early FLT3 inhibitor therapy in FLT3-mutant APML patients.

Mechanism of ITD mutation-induced leukemogenesis and model systems. Multiple signaling pathways are implicated in aberrant FLT3 activation in cells. The JMD of FLT3 contains auto-inhibitory function and maintains the kinase in an inactive conformation (62). The disruption of this region by an ITD results in constitutive activation of the FLT3 receptor (63). Activation of FLT3 results in the phosphorylation of proteins such as Gab2, SHP-2, and CBL, forming a complex that interacts with the $\mathrm{p} 85$ subunit of PI3K, thereby activating the anti-apoptotic PI3K pathway $(20,23)$. Serine/threonine protein kinase B (AKT) is shown to be phosphorylated and constitutively activated in $32 \mathrm{D}$ cells, which have been stably transfected with ITD (64).

The proliferative Ras/MAPK pathway is also activated with FLT3 signaling. Ba/F3 cells transfected with wild-type human FLT3 and stimulated with FL demonstrate transient activation of MAPK and phosphorylation of ERK1/2 (21). MEK inhibition reverses this activation and also inhibits the proliferative effect of FL on these cells. Both 32D and Ba/F3 cells transfected with FLT3-ITD alone show activation of MAPK $(64,65)$. Finally, MAPK is activated in primary AML blasts $(65,66)$.

STAT5 is involved in the regulation of self-renewal and differentiation of hematopoietic progenitor cells (67), and its aberrant activation has been demonstrated in human leukemia (68). STAT5 is constitutively phosphorylated and activated in cell lines transfected with FLT3-ITD mutations, as well as leukemia cell lines and primary AML blasts containing endogenous ITD mutations, but STAT5 is not activated in cells with wild-type FLT3, despite stimulation with FL $(64,65,69,70)$. FLT3-ITD-induced STAT5 activation was found to be independent of Src or Jak kinases in cell lines deficient for these kinases, and in vitro assays revealed that STAT5 is a direct target of FLT3 (71).

Yet, another potential mechanism of ITD mutations in leukemogenesis is the decreased expression of SHP-1, a phosphatase responsible for the down-regulation of multiple growth factor and cytokine signaling pathways. TF1 cells transfected with ITD induced a threefold decrease in SHP-1 activity (72). Decreased expression of SHP-1 results in increased proliferation in these cells. Also, in vitro treatment of FLT3-ITD cell lines and primary AML patient samples with an FLT3 inhibitor resulted in up-regulation of SHP-1 expression. Taken together, these data implicate SHP-1 as a tumor suppressor that has significantly decreased activity in ITD-positive AML (72).

Finally, FLT3-ITD also contributes to a block in cell differentiation. 32D cells transfected with ITD do not undergo granulocyte differentiation in response to granulocyte colony stimulatingfactor (G-CSF) (73). Subsequent investigation showed that the expression levels of $\mathrm{C} / \mathrm{EBP} \alpha$ and PU.1, both important modulators of myeloid differentiation, are repressed in the presence of FLT3-ITD (74). Treatment of these cells with an FLT3 inhibitor restored expression of these proteins and resulted in myeloid differentiation.

While FLT3-ITD has certainly been demonstrated as a transforming lesion in multiple cell models and clearly contributes strongly to leukemogenesis, it is not sufficient to fully transform primary hematopoietic cells or generate leukemia in mouse models. FLT3-ITD expression confers cytokine-independent growth in $32 \mathrm{D}$ and $\mathrm{Ba} / \mathrm{F} 3$ cell lines $(64,65)$, and induction of the signaling pathways discussed above. Mice injected with these transformed cell lines rapidly developed a leukemia-like illness $(64,66)$, but transplantation of primary BM cells retrovirally transduced with FLT3-ITD causes only a myeloproliferative disease (MPD) and not leukemia (75). Knock-in of heterozygous mutant ITD into murine FLT3 (FLT3 ${ }^{+/ \text {ITD }}$ ) causes a fatal MPD characterized by splenomegaly, leukocytosis, and myeloid expansion, but not frank leukemia (76). Consistent with cell models, these mice demonstrate expansion of dendritic cells and a block in B-cell development, caused by inefficient double strand break repair by nonhomologous end joining and failure of proper VDJ rearrangement in pro-B cells (77).

The heterozygous FLT3-ITD mutation does, however, cooperate with other molecular lesions in mouse models to generate both myeloid and lymphoid leukemia, such as MLL-AF9 (78), mutant C/EBP $\alpha$ (79), NUP98-HOXD13D (NHD13) fusion (80), and mutant nucleophosmin (NPMc+) (81), in agreement with accumulating evidence that leukemogenesis is a process that requires multiple genetic or epigenetic "hits." Interestingly, a mouse model of homozygous FLT3-ITD mirrored the increased disease severity of $\mathrm{CN}-\mathrm{LOH}$ seen in human malignancy with some homozygous mice developing spontaneous leukemia (77). Another group found similar results with homozygous FLT3-ITD knock-in mice, and by crossing these mice with FL knockout mice, also demonstrated that the homozygous FLT3-ITD phenotype is FL-independent, in contrast to the heterozygous FLT3-ITD mice, which had a milder phenotype in the absence of FL (82). These data suggest that ITD gene "dosage" is probably most important in LOH, but that loss of the wild-type allele also plays a functional role. This is in agreement with in vitro experiments showing enhanced FLT3 signaling in response to FL in FLT3-ITDexpressing cell lines, but no consistent effects of FL on STAT5 phosphorylation or other signaling pathways in primary AML blasts homozygous for ITD (83). 


\section{Tyrosine kinase domain point mutations}

Point mutations in the activation loop of the TKD of FLT3 were first described in de novo human leukemia in $2001(84,85)$. This area of the gene was interrogated for mutations because the corresponding domain in KIT was reported to harbor oncogenic activating point mutations (86). The first TKD mutations described involved aspartic acid residue D835, which is equivalent to D816 mutations in KIT, and less commonly, isoleucine I836. The D835 mutation is a missense mutation and confers a change in amino acid to tyrosine, histidine, valine, glutamic acid, or asparagine. In these newly diagnosed adult AML patients, TKD mutations occurred independently of ITD mutations (85).

Clinical relevance of TKD mutations in human leukemia. Tyrosine kinase domain mutations are less common than ITD mutations and do not appear to carry the same prognostic significance in leukemia. In fact, TKD and ITD mutations demonstrated differing gene-expression profiles in newly diagnosed pediatric AML patients (87). In large retrospective studies, TKD mutations were present in $\sim 7 \%$ of both adult and pediatric de novo AML (42, $48,85)$. In contrast to patients with ITD mutations, patients with D835 TKD mutations did not have elevated WBC counts compared to those with wild-type FLT3 $(48,85,88)$. In a large adult study, 17 of 979 (1.7\%) AML patients were positive for both ITD and TKD mutations, and 4 of 10 of these harbored the mutations on the same allele (42). In one pediatric study, 35\% of patients with TKD-mutant AML also harbored an 11q23/MLL rearrangement (MLL-r) (26\% had MLL-AF9) in comparison to $24 \%$ of FLT3-wild-type and only $2 \%$ of ITD-mutant AML patients with MLL-r (48).

Interestingly, in pediatric pre-B ALL, FLT3-TKD mutations are not infrequently associated with MLL-r. In 30 MLL patient samples tested, 5 (16\%) had mutations in the activation loop of TKD, and the residues involved were the same as demonstrated in AML, e.g., D835 (89). This group demonstrated that these TKD mutations resulted in constitutive activation of FLT3, an effect that could be reversed with a FLT3 small-molecule inhibitor. This was the first suggestion of clinically relevant TKD mutations in ALL, and implied a role for FLT3 inhibition in this subset of MLL-r patients. FLT3 mutations were also detected in 20-25\% of hyperdiploid (>50 chromosomes or DNA index $>1.14$ ) diagnostic pre-B ALL samples, and were associated with high levels of FLT3 expression $(90,91)$. In these small cohorts of hyperdiploid patients, it is unclear if FLT3 mutations affect prognosis, and larger prospective studies would need to determine this. These data nevertheless support a potential role for FLT3 inhibitors in this additional cohort of patients.

Arguably, the most clinically relevant role of FLT3-TKD mutations in leukemia is the development of a secondary point mutation detected at relapse, as a mechanism of resistance in patients with a pre-existing ITD mutation and after FLT3 inhibitor therapy. This important issue is discussed later in this review.

Mechanism of TKD mutation-induced leukemogenesis and model systems. In wild-type FLT3, the activation loop of the TKD normally maintains a "closed" conformation, preventing ATP and proteins from binding (63). The presence of a TKD mutation in this area is thought to open the activation loop, allowing for constitutive activation of the receptor. Phenylalanine substitutions for tyrosine residues in the kinase domain in a TKD-mutant mouse model revealed three critical residues involved in stabilizing the active conformation of the activation loop, one of which is the site of auto-phosphorylation in TKD mutants (92). Functional studies in Cos7 and 32D cells demonstrate that D835 TKD mutations result in auto-phosphorylation and constitutive activation of FLT3 independent of FL, in a similar manner to ITD mutations. D835 mutations also confer cytokine independence in $32 \mathrm{D}$ cells (85), further evidence of their gain of function, and transforming capability. Yamaguchi et al. also reported a robust increase in IL-3-independent proliferation in 32D cells expressing both TKD mutations and MLL-AF4 (93).

A murine BM transplant model using retroviral transduction compared disease phenotypes of FLT3-ITD and FLT3-TKD mutations in vivo, and surprisingly, TKD mutations caused an oligoclonal lymphoid disorder (both B- and T-lymphoid) compared to MPD seen with ITD mutations (94). The disease latency was longer than with ITD mutations, and mice with TKD mutations did not develop leukocytosis. Some myeloid expansion was seen in TKD-mutant BM, although the primary disease phenotype was lymphoid. In transfected $\mathrm{Ba} / \mathrm{F} 3$ and $32 \mathrm{D}$ cells, AKT and ERK1/2 were similarly phosphorylated with ITD and TKD mutations, but STAT5 was significantly more phosphorylated with the ITD mutation in both cell lines, and in transduced BM cells (94). In a recent report, a knock-in mouse model heterozygous for the D835Y mutation was generated, and shown to survive significantly longer than heterozygous FLT3-ITD knock-in mice (95). In contrast to the first model, in which FLT3 retroviral transduction likely resulted in overexpression of FLT3, the majority of these knock-in mice did develop myeloproliferative neoplasms (MPN), albeit with a less aggressive phenotype than the FLT3-ITD mice. Also, whereas a significant block in B-cell development and drastic reduction in the LT-HSC compartment were demonstrated in the FLT3-ITD mice, neither was observed in the FLT3-D835Y mice. Consistent with the other mouse model, STAT5 was significantly more phosphorylated in FLT3-ITD mice compared to FLT3-D835Y mice (95), suggesting that differential STAT5 signaling may explain the different phenotypes seen between FLT3-TKD and FLT3-ITD leukemia.

\section{FLT3 OVEREXPRESSION IN LEUKEMIA}

Gene-expression profiling of patients samples comparing pre-B ALL with MLL-r, pre-B ALL without MLL-r, and AML demonstrated that MLL-r leukemia contains a unique signature (96). MLL-r leukemia samples generally expressed high levels of genes associated with hematopoietic progenitor cells, suggesting that MLL is arrested at an earlier stage of development. Armstrong et al. found that the most consistently and impressively overexpressed gene in MLL-r leukemia is FLT3.

\section{MLL-r infant ALL}

Expanding on their gene-expression profiling data, Armstrong et al. found that overexpression of wild-type FLT3 is an activating lesion in SEMK2, a $t(4 ; 11)$ MLL-r pre-B ALL cell line (89). Strikingly, FLT3 is basally phosphorylated and constitutively 
activated in this cell line, to an even higher extent than in the AML cell line MV4;11, which contains an FLT3-ITD mutation as well as $\mathrm{t}(4 ; 11)$. This was in contrast to two pre-B ALL cell lines without MLL-r or FLT3 overexpression, and the pre-B ALL cell line RS4;11 which contains $\mathrm{t}(4 ; 11)$ but does not demonstrate FLT3 overexpression. FLT3 overexpression in SEMK2 cells is due to intra-chromosomal amplification of the gene locus, with each cell containing one to two amplicons of 10 copies of the gene. An FLT3 small-molecule inhibitor demonstrated selective cytotoxicity and reversal of FLT3 activation in SEMK2 and MV4;11 cells, and showed anti-tumor effect in vivo in a leukemia mouse model engrafted with SEMK2, but not with RS4;11 cells (89). It was then shown that CEP-701 (lestaurtinib), a smallmolecule FLT3 inhibitor, is selectively cytotoxic in infant ALL patient samples with MLL-r and FLT3 overexpression, as well as in FLT3-overexpressing hyperdiploid ALL $(97,98)$. Lestaurtinib has also been shown to reverse FLT3 auto-phosphorylation in FLT3overexpressing ALL patient samples (97). Importantly, subsequent studies of infant ALL patients revealed a worse overall prognosis with high levels of FLT3 expression in MLL-r leukemia $(99,100)$. These data serve as the pre-clinical rationale for FLT3 inhibition in FLT3-overexpressing MLL-r ALL in infant leukemia.

\section{Hyperdiploid ALL}

Gene-expression analysis of a large number of diagnostic pediatric ALL cases also demonstrated overexpression of FLT3 in hyperdiploid (>50 chromosomes) samples (101). To our knowledge, there is no pre-clinical or clinical study of FLT3 inhibition in hyperdiploid ALL, possibly due to the relatively good clinical outcomes of these patients with traditional chemotherapy.

\section{Mechanism of FLT3 overexpression-induced leukemogenesis and model systems}

Constitutive FLT3 signaling and the leukemogenic role of FLT3 overexpression in these subsets of ALL is likely caused either by concomitant FLT3-TKD mutations, or the co-expression and autocrine signaling of FL. In model systems, Ba/F3 cells overexpressing wild-type FLT3 did not become cytokine-independent, in contrast to FLT3-mutant-expressing cells. However, FLT3 overexpressing $\mathrm{Ba} / \mathrm{F} 3$ cells engrafted into Balb/c mice did cause leukemia, which may have been secondary to murine FL expression in this model (69). The transplantation of Balb/c mice with FLexpressing BM also caused leukemia, albeit with a longer latency (102), again suggesting an autocrine or paracrine role of FL in these models.

\section{FLT3-TARGETED THERAPY}

\section{DISCOVERY, PRE-CLINICAL EVIDENCE AND PHARMACODYNAMICS ASSESSMENT OF FLT3 INHIBITORS}

\section{First small-molecule inhibitors: in vitro proof of principle}

Similar to the small-molecule tyrosine kinase inhibitor imatinib, FLT3 inhibitors act by competitively binding to the ATP-binding site. The first FLT3 small-molecule kinase inhibitors reported were AG1295 and AG1296, which were selectively cytotoxic to cell lines transfected with FLT3-ITD and primary patient samples with ITD mutations, and demonstrated inhibition of downstream FLT3 signaling in vitro $(103,104)$. Despite achievable IC50's in the nanomolar range, these initial inhibitors are not soluble and therefore not biologically available.

CEP-701 (lestaurtinib) is an orally available indolocarbazole derivative with activity against multiple kinase receptors. It was discovered through a small-molecule inhibitor library screen, and was subsequently found to selectively inhibit autophosphorylation of constitutively active FLT3 in vitro, as well as prolong survival of an FLT3-ITD mouse model in vivo (66). Furthermore, lestaurtinib was selectively cytotoxic to FLT3-ITD primary pediatric AML samples compared to FLT3-wild-type or FLT3-TKD-mutant patient samples (105). Aberrant overexpression of wild-type FLT3 in infant MLL-r and hyperdiploid ALL can cause constitutive FLT3 activation; therefore, lestaurtinib was next investigated in cell lines and primary patient samples with these lesions. Selective cytotoxicity, inhibition of FLT3 phosphorylation, and overall suppression of FLT3-dependent survival were demonstrated with lestaurtinib (97). These pre-clinical data were the supporting evidence to investigate lestaurtinib in clinical trials.

Similar to the lestaurtinib story, others investigated PKC412, a small-molecule developed as a protein kinase $\mathrm{C}$ inhibitor, but was found to have inhibitory activity against multiple class III RTK, including PDGFR, VEGFR, and FLT3 (106). PKC412 (midostaurin) inhibits the proliferation of transformed cell lines transfected with activating mutations of FLT3, and shows clinical activity in mice with FLT3-induced MPD $(75,106)$.

\section{Sequential delivery of FLT3 inhibitors and chemotherapy}

Incorporation of FLT3 inhibitors into existing chemotherapy regimens was studied pre-clinically, first in FLT3-ITD-expressing cell lines and primary patient AML blasts. In vitro, pre-treatment with lestaurtinib followed by chemotherapy agents is antagonistic, whereas simultaneous therapy or treatment with lestaurtinib after chemotherapy has a synergistic cytotoxic effect (107). FLT3 inhibitors arrest FLT3-activated cells in G1 phase of cell cycle, rendering these cells insensitive to drugs such as cytarabine and etoposide that exert their cytotoxic effects on cells in active $S$ phase. Surprisingly, AML cells with either ITD or wild-type FLT3 showed synergistic cytotoxicity with lestaurtinib and daunorubicin. This effect is likely due to the competitive binding of these drugs to the same plasma protein, increasing their free concentrations, which could potentially increase systemic toxicity of daunorubicin. Treating cells with chemotherapy first, followed by lestaurtinib, surmounts both of these undesirable combination effects. Similar combination experiments in infant MLL-r ALL cells overexpressing wild-type FLT3 were performed, and again synergy was observed using chemotherapy first, followed by lestaurtinib (108). These models provided invaluable guidance moving forward with FLT3 inhibitors in clinical trials.

\section{Development of correlative assay to determine efficacy (PIA)}

The hypothesis of kinase inhibitors in malignancies is that inhibition of the kinase receptor signaling will result in anti-tumor effect and concomitant clinical response. However, acquiring tissue to compare signaling changes before and after therapy is challenging. Additionally, plasma drug concentration does not necessarily reflect therapeutic efficacy, since variances in plasma protein binding affects the level of free/active drug. For these reasons, a useful 
surrogate in vitro assay was developed to assess the efficacy of FLT3 inhibition in patients. A plasma inhibitory assay (PIA) utilizes an FLT3-ITD transfected cell line, TF1-ITD, mixed with patient plasma at various time points during treatment, to measure levels of FLT3 phosphorylation (109). This method reliably correlated with patient responses to treatment. In a phase 1 clinical trial with lestaurtinib, a PIA of $85 \%$ or greater correlated with patient clinical response to drug and reflects an approximate threshold for FLT3 inhibition in vivo (110).

\section{FLT3 INHIBITORS IN LEUKEMIA}

This section will summarize the best-characterized FLT3 inhibitors in use in pediatric leukemia, and discuss some relevant adult clinical trial data. A summary of recently completed or ongoing pediatric clinical trials with FLT3 inhibitors, along with the NCT identifying numbers, is shown in Table 1.

\section{CEP-701/lestaurtinib}

CEP-701/lestaurtinib in adult leukemia. The first use of FLT3 inhibitors in leukemia patients was a small phase $1 / 2$ trial of lestaurtinib monotherapy in adult patients with heavily pretreated, refractory/relapsed AML. Five of 14 patients achieved some clinical response, with a significant decrease in marrow or circulating peripheral blasts, and little observed toxicity. PIAs were performed on patient plasma as described above, and demonstrated inhibition of FLT3 activity down to a target level of $10-15 \%$ in 8 of 14 evaluable patients; 5 of these were the patients with clinical responses. Interestingly, the other patient samples with good FLT3 inhibition did not demonstrate cytotoxicity in vitro or clinical response, suggesting a resistant phenotype. Clinical responses lasted 2 weeks to 3 months (110).

A phase 2 study of lestaurtinib followed, in older adults with newly diagnosed AML who were unsuitable candidates for conventional chemotherapy (113). Drug was again generally well tolerated with mild GI toxicities. Two of 29 patients had grade 4 thrombocytopenia, and one died from a CNS hemorrhage. Three of 5 patients with mutant FLT 3 and 5 of 22 patients with wild-type FLT3 experienced some clinical response with decreased blasts, which again correlated with the degree of FLT3 inhibition by PIA data. Again, responses with monotherapy were short-lived, generally only sustained for several weeks.

Table 1 | Pediatric clinical trials with FLT3 inhibitors: recently completed or ongoing studies

\begin{tabular}{|c|c|c|c|c|c|}
\hline Trial identifier & Phase & Status & Patients & Drug(s) & Results \\
\hline NCT00469859 & $1 / 2$ & Completed & Relapsed AML & Lestaurtinib & Not published \\
\hline COG & & & & (CEP-701) & \\
\hline \multirow[t]{2}{*}{ AAML06P1 } & & & & Cytarabine & \\
\hline & & & & Idarubicin & \\
\hline NCT00557193 & 3 & Completed & Newly diagnosed ALL & Lestaurtinib & Not published \\
\hline \multirow[t]{3}{*}{ COG-AALL0631 } & & & Infants $<12 \mathrm{~m}$ & (CEP-701) & \\
\hline & & & & Chemotherapy & \\
\hline & & & & (modified P9407) & \\
\hline \multirow[t]{2}{*}{ NCT00866281 } & $1 / 2$ & Recruiting & MLL-r infant ALL & Midostaurin & $\mathrm{N} / \mathrm{A}$ \\
\hline & & & FLT3-mutant AML & $(\mathrm{PKC} 412)$ & \\
\hline NCT01411267 & 1 & Completed & Relapsed/refractory ALL & Quizartinib (AC220) & Not published; Abstract \\
\hline \multirow[t]{3}{*}{ TACL 2009-004 } & & & or AML & Cytarabine & presented at ASH 2013 \\
\hline & & & & Etoposide & \\
\hline & & & & Methotrexate & \\
\hline NCT00908167 & 1 & Recruiting & Relapsed/refractory ALL & Sorafenib & N/A; although pilot \\
\hline St. Jude & & & or $\mathrm{AML}$ & Cytarabine & cohort data published: \\
\hline RELHEM & & & & Clofarabine & Inaba et al. (111) \\
\hline NCT00665990 & 1 & Recruiting & Refractory ALL, AML or & Sorafenib & $\mathrm{N} / \mathrm{A}$ \\
\hline St. Jude & & & solid tumors (solid tumor & Bevacizumab & \\
\hline ANGIO1 & & & portion completed) & Low dose-cytoxan & \\
\hline NCT01371981 & 3 & Recruiting & Newly diagnosed AML & Sorafenib & $\mathrm{N} / \mathrm{A}$ \\
\hline \multirow[t]{3}{*}{ COG AAML1031 } & & & & Bortezomib & \\
\hline & & & & Chemotherapy (ADE & \\
\hline & & & & or ADE/MA based) & \\
\hline NCT01445080 & 1 & Completed & $\begin{array}{l}\text { Refractory ALL, AML or } \\
\text { solid tumors }\end{array}$ & Sorafenib & $\begin{array}{l}\text { Published; Widemann } \\
\text { et al. (112) }\end{array}$ \\
\hline
\end{tabular}


A randomized phase 2 study of salvage chemotherapy in combination with lestaurtinib was completed in adult patients with FLT3-mutant AML in first relapse (114). There was no difference in OS between the two arms, but importantly, only $58 \%$ of patients treated with lestaurtinib achieved FLT3 inhibition down to target levels, and only $27 \%$ sustained FLT3 inhibition. FLT3 inhibition correlated well with drug response, whereas plasma drug concentration did not correlate well with response. These results validate the importance of the correlative laboratory studies in determining patient response to FLT3 inhibitors.

CEP-701/lestaurtinib in pediatric leukemia. Based on the preclinical data in pediatric leukemia with either activating FLT3 mutations or overexpression, lestaurtinib was moved into pediatric trials. In 2007, the COG opened a phase $1 / 2$ pilot study of lestaurtinib in relapsed/refractory AML patients with FLT3 mutations. Dose level 1 was $50 \mathrm{mg} / \mathrm{m} 2$ and dose level 2 was $62.5 \mathrm{mg} / \mathrm{m} 2$, given orally, in combination with idarubicin and cytarabine. Based on the drug-sequence pre-clinical data, chemotherapy was given on days $1-4$, and lestaurtinib given on days 5-28. The study completed accrual in 2010, and data are not yet published. Primary outcomes studied were safety/tolerability and $>80 \%$ inhibition of FLT3 phosphorylation in the majority of patients at trough time points.

A phase 3, randomized COG trial with lestaurtinib, in combination with standard chemotherapy, opened in 2008 for newly diagnosed infant ALL (COG-AALL0631). The study has recently completed, and results are pending. Intermediate risk (MLL-r and $>90$ days old) and high-risk patients (MLL-r and $<90$ days old) were randomized to receive lestaurtinib after induction therapy, with a primary study outcome of EFS. Secondary outcomes include correlative laboratory studies, such as PIAs to determine inhibition of FLT3 phosphorylation. MLL wild-type infants did not receive lestaurtinib.

\section{PKC412/midostaurin}

PKC412/midostaurin in adult leukemia. A phase 2 clinical trial of midostaurin in 20 adults with relapsed or refractory FLT3mutated MDS or AML showed that drug was generally well tolerated, though 2 patients suffered fatal pulmonary events of uncertain etiology (115). Peripheral blood blasts decreased by at least $50 \%$ in $14(70 \%)$ of patients, and this result was sustained for at least 4 weeks in 7 (35\%) patients. PIAs were not used in this trial, but peripheral blasts recovered at early time points demonstrated inhibition of FLT3 phosphorylation in patients with good clinical responses.

This was followed by a phase 2B study in 95 adults with relapsed or refractory AML or those unable to receive conventional chemotherapy. Patients had wild-type or mutated FLT3 and were randomly assigned to receive oral midostaurin monotherapy at either 50 or $100 \mathrm{mg}$ twice daily. Interestingly, $71 \%$ of patients with mutant FLT3 experienced a hematological response with at least $50 \%$ reduction in peripheral blasts, whereas only $42 \%$ of patients with wild-type FLT3 demonstrated a clinical response (116). A phase $1 \mathrm{~B}$ study combined midostaurin with standard induction chemotherapy in three different schedules, in patients with newly diagnosed AML. At tolerable doses of $50 \mathrm{mg}$ twice daily, there was an $80 \%$ complete response (CR) rate in these patients; specifically, 74\% CR rate in FLT3-wild-type patients and 92\% CR rate in FLT3-mutant patients (117). These results provided rationale for a large, recently completed phase 3 clinical trial of midostaurin for adult AML with FLT3-mutant leukemia (clinical trial identifier NCT00651261); results are not yet available ${ }^{1}$.

PKC412/midostaurin in pediatric leukemia. In pediatrics, a phase $1 / 2$ clinical trial open in Europe and some U.S. centers is currently recruiting MLL-r infant ALL and FLT3-mutant AML patients to receive midostaurin as a single agent, with a primary outcome of determining the maximally tolerated dose (MTD). Secondary outcomes include safety/tolerability, PKs, preliminary efficacy of the drug in these diseases, and laboratory correlatives, including evaluation of FLT3 phosphorylation before and after drug.

\section{AC220/quizartinib}

Quizartinib, a small-molecule inhibitor engineered specifically for FLT3, is incredibly potent and selective compared to the previous "first-generation" FLT3 inhibitors, with low nanomolar concentrations of quizartinib achieving inhibition in vitro $(118,119)$.

AC220/quizartinib in adult leukemia. In a phase 1 adult study, 76 patients with relapsed or refractory AML received quizartinib monotherapy (120). Hematological responses were seen in $53 \%$ of patients with FLT3-ITD mutations, and PIAs revealed near-total inhibition of FLT3 phosphorylation in nearly all cases. Subsequently, a phase 2 study of relapsed/refractory AML patients, all containing ITD mutations, recently completed accrual, and results were presented in abstract form at the 2012 American Society of Hematology (ASH) meeting $(121,122)$. As monotherapy, quizartinib impressively induced a CR or a CR with incomplete blood count recovery (CRi) in 9 of 17 patients (53\%). Ongoing adult studies are now evaluating quizartinib in combination with chemotherapy (NCT01390337) ${ }^{1}$.

AC220/quizartinib in pediatric leukemia. The Therapeutic Advances in Childhood Leukemia and Lymphoma (TACL) consortium recently completed a pilot study of quizartinib in combination with cytarabine and etoposide, in pediatric patients with MLL-r ALL or relapsed/refractory AML. Chemotherapy was administered on days 1-5 and oral quizartinib was given days 7-28, for up to two courses of therapy. PIAs were obtained to determine biological efficacy of FLT3 inhibition. Preliminary results were presented at the 2013 annual ASH conference and showed good tolerability of drug (123). The correlative PIA assays demonstrated near-total (>99\%) inhibition of FLT3 phosphorylation after quizartinib. Importantly, four of six patients with FLT3-ITD-mutant AML achieved a CR or CRi and the other two ITD patients had stable disease. These results support further testing of quizartinib in pediatric leukemia, particularly in FLT3-ITD-mutant AML.

${ }^{1}$ www.clinicaltrials.gov (accessed on July, 2014). 


\section{Sorafenib}

Sorafenib in adult leukemia. Three phase 1 trials with sorafenib in adults with relapsed/refractory AML have been published to date. The first study treated 16 patients and found a hematological response ( $>50 \%$ reduction in peripheral or BM blasts) in patients with ITD mutations but not in those with wild-type FLT3 (124). The second study included one patient with an ITD mutation who achieved a CR with sorafenib alone (125). In the third study, the best response was stable disease in 11 of 15 patients, but 2 of these 11 were the only patients with ITD mutations (126).

A phase $1 / 2$ adult study evaluated 10 relapsed AML patients with sorafenib in the dose-finding phase, and then treated 51 newly diagnosed AML patients with a combination of sorafenib, cytarabine, and idarubicin (127). PIAs demonstrated complete inhibition of FLT3 phosphorylation. Impressively, 38 (75\%) of all patients achieved a CR, and all patients with ITD mutations achieved a CR or a CRi. One year-OS rate for all patients was 74\%. A phase 2 German study randomized elderly AML patients to receive placebo or sorafenib, followed by cytarabine (128). No differences in EFS or OS were noted, but this study was limited by the patient population and the relatively small number of ITD-positive patients (28 of 197 or $14 \%$ ).

Sorafenib in pediatric leukemia. Recent early phase pediatric clinical trial reports with sorafenib appeared promising. Inaba et al. published results from a pilot group of 12 patients with relapsed/refractory AML. Patients received sorafenib in combination with clofarabine and cytarabine in the following manner: oral sorafenib on days $1-7$, sorafenib plus IV clofarabine/cytarabine on days 8-12, and single-agent sorafenib on days 13-28 if tolerated (111). Grade 3 dose limiting toxicity (DLT) of hand-foot skin reaction was reported at a dose of $200 \mathrm{mg} / \mathrm{m} 2$, thus $150 \mathrm{mg} / \mathrm{m} 2$ was subsequently used and well tolerated. Five of five patients with ITD mutations achieved a CR or CRi, and three of seven patients with wild-type FLT3 also achieved a CR. In vitro inhibition of FLT3 downstream signaling protein phosphorylation was demonstrated in most of these patient samples upon treatment with sorafenib. Interestingly, conversion of sorafenib to its active metabolite, sorafenib N-oxide, was three to four times higher in children than previously reported in healthy adult and adults with leukemia. Although this may have contributed to increased nonDLT skin reactions seen in children, the active metabolite is also a more potent inhibitor of FLT3-ITD (111).

Watt and Cooper described three case reports of pediatric relapsed/refractory AML that achieved sustained remissions with sorafenib in combination with chemotherapy. Significant toxicities were noted in two of three patients, but efficacy was demonstrated in each case. Sorafenib combination therapy served as a bridge to transplant in one of these cases, a 7-year old male with ITD-mutant AML, and that patient remains in remission 21 months post-transplant (129). Finally, a COG phase 1 consortium trial at the NCI investigated single-agent sorafenib in refractory solid tumors or leukemia. The MTD for solid tumors and leukemia are 150 and $200 \mathrm{mg} / \mathrm{m} 2$ twice daily, respectively. Eleven leukemia patients (eight AML and three ALL) were enrolled. Two AML patients with ITD mutations achieved a CR and went off study to undergo stem cell transplantation (112).
Given these encouraging results, the current phase 3 COG randomized trial for newly diagnosed AML incorporates sorafenib for pediatric FLT3-ITD AML. This trial non-randomly assigns ITD-mutant patients with high allelic ratios $(>0.4$, as previously discussed, HR-ITD) to Arm C, which includes sorafenib in addition to chemotherapy. Simultaneous sorafenib begins immediately in induction therapy and continues throughout the treatment protocol. It is recommended for all high-risk patients to receive a stem cell transplant in first CR, if any suitable donor is available. For HR-ITD patients, this trial also includes a maintenance phase with single-agent sorafenib for 1 year, beginning between day 40-80 either after transplant or after finishing chemotherapy.

\section{ASP2215}

ASP2215, a promising new small-molecule inhibitor, demonstrated potent kinase inhibition of FLT3, LTK, ALK, and AXL (130). Furthermore, ASP2215 inhibited the growth of cell lines expressing FLT3-ITD or FLT3-D835-TKD mutations. The same group also showed that ASP2215 induced complete tumor regression in MV4;11 xenografts as a single agent (130) and in combination with chemotherapy (131). ASP2215 is currently being investigated in adult relapsed/refractory AML with a multi-institutional phase $1 / 2$ trial in the United States (NCT02014558) and a phase 1 trial in Japan (NCT02181660) ${ }^{1}$.

\section{OTHER THERAPEUTIC APPROACHES IN FLT3-ACTIVATED LEUKEMIA} Role of HSCT in first remission in patients with FLT3-ITD mutations

The beneficiary role of HSCT in first remission for FLT3-ITD AML has been controversial, although due to generally poor outcomes in this cohort with chemotherapy alone, HSCT is rapidly becoming the standard of care $(132,133)$. With improved transplant-related mortality in recent years, the benefit of HSCT in pediatric highrisk AML has become more apparent. Two recent pediatric reports show no significant difference in outcomes between high-risk (including FLT3-ITD patients) and standard-risk AML patients receiving $\mathrm{HSCT}$ in first $\mathrm{CR}$, demonstrating that HSCT abrogates the poor outcomes associated with high-risk pediatric AML $(134,135)$. The current phase 3 COG randomized trial for newly diagnosed AML, as mentioned, non-randomly assigns HR-ITD patients to Arm $\mathrm{C}$ with sorafenib. Patients may continue on study as long as they achieve and maintain remission status $(<5 \%$ blasts at end of induction II or better). After intensification I, these patients may proceed with allogeneic HSCT if any appropriate donor is available, and if no donor is available, they may receive another intensification cycle (with ongoing sorafenib). This is not a randomized design, but the outcomes of these patients compared to historical controls are hypothesized to show improvement with HSCT.

\section{Role for maintenance FLT3 inhibitor after hematopoietic stem cell transplantation}

Adult leukemia. There are good data in the adult literature to suggest a role for sorafenib as maintenance therapy in FLT3ITD AML, particularly after HSCT. Several smaller studies of relapsed adult FLT3-ITD AML post-HSCT reported some CRs and other good responses with single-agent sorafenib after allogeneic HSCT (136-138). A recent retrospective review of 65 FLT3ITD AML patients compared single-agent sorafenib efficacy in 
newly relapsed patients who had previously received conventional chemotherapy versus those who had a prior HSCT (139). In this series, the patients who had received a prior HSCT achieved longer remission before treatment failure compared to those receiving chemotherapy previously (197 versus 136 days, $p=0.0305$ ) and also achieved "deeper" remissions, with a strikingly $24 \%$ of postHSCT patient achieving a complete molecular remission (compared to $8 \%$ with prior chemotherapy). The authors of this series and others have proposed a possible immuno-modulatory effect of sorafenib after transplant in these patients, though a mechanism for this effect is not yet elucidated. Ongoing adult clinical trials are studying post-transplant sorafenib in greater detail (NCT01578109, NCT01398501). Also, a phase 1 study is evaluating quizartinib as maintenance therapy after allogeneic transplant in adult AML (NCT01468467), and a phase 2 study is investigating midostaurin as maintenance after allogeneic transplant in FLT3-ITD adult AML (NCT01883362) ${ }^{1}$.

Pediatric leukemia. There is limited but promising experience with post-HSCT sorafenib in pediatric AML. In Seattle, 15 FLT3ITD pediatric AML patients received sorafenib post-HSCT: 10 after relapse and 5 prophylactically. Seven of the 10 relapsed patients remain in a second CR at a median of 12.5 months post start of therapy, and 4 of the 5 patients given sorafenib prophylactically remain disease-free at a median of 10 months (Pollard, unpublished data). Interestingly, one patient who received prophylactic sorafenib post-HSCT was discovered to have an ITDnegative clone at relapse, suggesting clonal evolution. The current phase 3 COG-AAML1031 trial incorporates maintenance FLT3 inhibitor therapy after transplant. FLT3-ITD patients on this study will have received sorafenib in pre-HSCT therapy, and upon count recovery post-HSCT, will resume sorafenib as a single agent until day 364 post-transplant. Effectiveness of this novel maintenance FLT3 inhibitor therapy is yet to be determined. Also, the effect of sorafenib on graft versus host disease, and therefore, potentially graft versus leukemia effect, is not known. The role of other FLT3 inhibitors, such as quizartinib, after stem cell transplant in FLT3activating leukemia has not yet been addressed in the pediatric population.

\section{CHALLENGES AND FUTURE APPROACH TO FLT3 INHIBITION FLT3 INHIBITOR RESISTANCE: BOTH CHALLENGE AND VALIDATION OF FLT3 ADDICTION}

Despite promising biological activity in pre-clinical models and good clinical activity of various FLT3 inhibitors in early phase clinical trials, effective therapeutic targeting of FLT3 has proved challenging. Resistance to targeted therapy often develops due to pharmacokinetic (extrinsic) or pharmacodynamic (intrinsic) forces. The mechanisms of resistance to FLT3 inhibitors can be further classified as extrinsic, receptor-intrinsic, or cell-intrinsic (140). Primary resistance occurs from the onset of treatment, and secondary resistance occurs at relapse after initial response to FLT3 inhibitors.

\section{Extrinsic mechanisms: pharmacokinetic barriers}

Trials with first-generation FLT3 inhibitors showed difficulty achieving adequate plasma free drug concentrations. Hepatic
CYP3A4-mediated metabolism of midostaurin results in two metabolites with decreased FLT3-specific activity. Midostaurin and its metabolites can also induce CYP3A4, resulting in highly unreliable concentrations of drug (141). Midostaurin must therefore be given with caution with other medications affecting CYP3A4 activity. Lestaurtinib is particularly highly bound to plasma protein, and competes with anthracyclines for alpha-1 acid glycoprotein binding sites, resulting in decreased free concentration of lestaurtinib, and potentially increased anthracycline toxicity. Also, medications such as azole antifungals can affect the metabolism of certain FLT3 inhibitors (142).

\section{Cell-intrinsic mechanisms}

Activation of alternate pathways and survival signaling. Primary resistance to FLT3 inhibitors can occur through the activation and up-regulation of alternate survival signaling pathways. Anti-apoptotic pathways involving Bcl-x and BCL2 are differentially activated in FLT3-ITD compared to FLT3-wild-type AML (143). Interestingly, BCL2 is not down-regulated in FLT3-ITD cells upon FLT3 inhibitor treatment, signifying a mechanism of primary resistance. Treatment with the BH3 mimetic ABT737 restored sensitivity to FLT3 inhibition, suggesting a role for dual targeting of FLT3 and BCL2 (144). MV4;11 cells are homozygous for ITD, and upon developing resistance to midostaurin, demonstrate up-regulation of anti-apoptotic genes MCL-1 and C-KIT by microarray and PCR compared to parental MV4;11 cells (145). Knapper et al. demonstrated that AML primary cells show variable cytotoxicity to FLT3 inhibition with midostaurin or lestaurtinib and retain activation of STAT5 and MAPK pathways even with near-complete inhibition of FLT3 phosphorylation (146). In another investigation, human AML cell lines in prolonged culture with FLT3 inhibitors were selected for resistant clones, and sequencing of these clones revealed no secondary TKD mutations. FLT3 was completely inhibited in these resistant cells, yet the phosphorylation and activation of STAT5, AKT, and/or MAPK was maintained (147). Furthermore, MEK or PI3K inhibition restored sensitivity of these cells to FLT3 inhibition. Piloto et al. also found that two of the resistant cell lines had developed new, activating $\mathrm{N}$-Ras mutations that were not present in the parental sensitive cell line. Taken together, these reports are supporting in vitro evidence for the activation of FLT3-independent pathways, promoting cell survival and proliferation during FLT3 inhibitor therapy.

Another proposed mechanism of resistance involves the FL. Sato et al. showed that FL levels are significantly higher following intensive chemotherapy, and are strikingly high in relapsed AML patients (148). Adding exogenous FL to AML samples in vitro (at levels similar to that seen in patients) conferred relative resistance to five different FLT3 inhibitors. This spike of FL after chemotherapy may therefore represent an obstacle to FLT3 inhibition, and suggests a role for the development of novel FL inhibitors. Reducing chemotherapy intensity could attenuate the rise in FL and may be an important consideration. In another model, investigators compared the gene-expression profiles of MV4;11 cells resistant or sensitive to FLT3 inhibitor ABT869 (149). The resistant cells showed up-regulation of FL and survivin, and up-regulated survivin led to decreased apoptosis and increased number of cells in $S$ phase. They propose that an increase in FL in the resistant cells 
caused increased STAT activation, which in turn led to increased survivin. This group further showed that survivin expression was directly regulated by activated STAT3. Combining ABT869 with the STAT inhibitor IDRE804 reversed this effect, and the combination demonstrated therapeutic synergy in vivo.

Microenvironment and stromal protection. Clinical studies with single-agent FLT3 inhibitors demonstrate good clearance of circulating peripheral blasts, but a marginal or delayed effect on blasts in the BM, suggesting a protective role of the BM microenvironment. Leukemic stem cells (LSC), like normal hematopoietic stem cells, reside in stromal "niches" with specialized conditions for optimal growth and survival (150). Sequestered in these niches, it is hypothesized that LSCs may evade chemotherapy or targeted therapy-induced cell death. Interestingly, in stroma-like conditions in vitro, FLT3-ITD AML blasts become resistant to FLT3 inhibitor effects, and in fact demonstrate expansion $(151,152)$. CXCR4 and its ligand, SDF-1, are important regulators of stromal/leukemia cell interactions $(153,154)$. FLT3 and its ligand FL have been shown to modulate surface CXCR4 expression, which is up-regulated in FLT3-ITD AML patient samples $(155,156)$. Subsequently, pre-clinical models have shown that CXCR4 inhibition enhances the sensitivity of FLT3-ITD AML cells to FLT3 inhibition $(157,158)$. An ongoing phase 1 trial in adults is investigating the combination of CXCR4 inhibitor AMD3100 (Plerixafor) and sorafenib in relapsed/refractory FLT3-ITD AML (NCT00943943). It has been demonstrated that Plerixafor enhances the response of MLL-r ALL cells to FLT3 inhibition in xenografts, suggesting that this dual targeting may prove useful in this high-risk subset of pediatric leukemia patients (159).

\section{Receptor-intrinsic mechanisms}

Acquired point mutations. In BCR-ABL leukemia, the selection of clones that harbor mutations in the ATP-binding pocket and prevent the binding of imatinib is the most common cause of drug resistance (160). Likewise, the development of TKD point mutations at relapse after FLT3 inhibitor therapy is well described, and is a significant mechanism of secondary resistance in FLT3-ITD AML patients (161). This phenomenon is compelling evidence that FLT3-ITD represents a driver mutation in AML, and that the ITD activating mutation can render a state of "oncogene addiction" in this disease. Prior to reports of acquired mutations in patient samples, forced resistance to FLT3 inhibitors in vitro predicted the development of acquired TKD mutations at certain key residues $(162,163)$. Many of these have since been confirmed in patients, and Table 2 summarizes acquired point mutations that have been described after FLT3 inhibitor therapy. The first case report described a novel FLT3-TKD mutation N676K, discovered at relapse in an FLT3-ITD AML patient after midostaurin monotherapy (164). 32D cells transfected with ITD-N676K FLT3 confirmed in vitro resistance to midostaurin, relative to cells transfected with FLT3-ITD. The second report described a FLT3-ITD-positive, BCR-ABL-negative CML patient in blast crisis, who acquired the mutation A848P at relapse after a 9-month response to alternating therapy with sunitinib and sorafenib (165). $\mathrm{Ba} / \mathrm{F} 3$ cells with ITD-A848P FLT3 were resistant to both sunitinib and sorafenib, but maintained sensitivity to midostaurin. Neither
Table 2 | Acquired point mutations in FLT3-ITD patients after FLT3 inhibitor therapy.

\begin{tabular}{|c|c|c|c|c|}
\hline Mutation & Disease & Therapy & Reference & $\begin{array}{c}\text { Validated } \\
\text { in vitro }\end{array}$ \\
\hline N676K & $A M L$ & PKC412 & Heidel et al. (164) & $32 \mathrm{D}$ \\
\hline A848P & $\begin{array}{l}\text { CMML } \\
\text { Relapsed } \\
\text { blast crisis }\end{array}$ & $\begin{array}{l}\text { Sunitinib and } \\
\text { sorafenib }\end{array}$ & $\begin{array}{l}\text { von Bubnoff et al. } \\
\text { (165) }\end{array}$ & $\mathrm{Ba} / \mathrm{F3}$ \\
\hline \multirow[t]{3}{*}{ F691L } & AML & AC220 & Smith et al. (161) & $\mathrm{Ba} / \mathrm{F3}$ \\
\hline & AML & AC220 & Albers et al. (167) & $\mathrm{Ba} / \mathrm{F3}$ \\
\hline & $\begin{array}{l}\mathrm{AML} \\
\text { (pediatric) }\end{array}$ & Sorafenib & Baker et al. (168) & \\
\hline \multirow[t]{3}{*}{ D835Y } & AML & AC220 & Smith et al. (161) & $\mathrm{Ba} / \mathrm{F3}$ \\
\hline & AML & Sorafenib & Man et al. (169) & \\
\hline & $\begin{array}{l}\text { AML } \\
\text { (pediatric) }\end{array}$ & Sorafenib & Baker et al. (168) & \\
\hline D835V & AML & AC220 & Smith et al. (161) & \\
\hline D835F & AML & AC220 & Smith et al. (161) & \\
\hline \multirow[t]{2}{*}{$\mathrm{D} 835 \mathrm{H}$} & AML & Sorafenib & Man et al. (169) & $\mathrm{Ba} / \mathrm{F} 3$ \\
\hline & $\begin{array}{l}\text { AML } \\
\text { (pediatric) }\end{array}$ & Sorafenib & Baker et al. (168) & \\
\hline D651G & AML & Sorafenib & Zhang et al. (170) & \\
\hline G619C & $\mathrm{AML}$ & Sorafenib & Zhang et al. (170) & \\
\hline $1687 \mathrm{~F}$ & AML & Sorafenib & Zhang et al. (170) & \\
\hline E858K & AML & Sorafenib & Zhang et al.(170) & \\
\hline
\end{tabular}

mutation was detected prior to FLT3 inhibitor therapy. Additional acquired mutations are likely to emerge, based on screening in vitro models, such as the highly resistant Y842C mutation (166).

A recent report evaluated paired pre-treatment and relapsed samples from eight adult FLT3-ITD AML patients treated with quizartinib monotherapy, all of which relapsed after initial good marrow responses (161). Using single molecule real-time (SMRT) sequencing, the ITD alleles were analyzed and all eight patients had developed additional point mutations in the kinase domain at relapse that were not detected pre-treatment. Four patients had developed polyclonal resistance with multiple point mutations, validating the significant selective pressure of quizartinib on these leukemic clones. In this report, TKD mutations in patients were confined to residues F691 and D835. In vitro cell-based assays containing these mutations confirmed resistance to quizartinib, and demonstrated cross-resistance to sorafenib (161). Other reports have identified or confirmed TKD mutations after FLT3 inhibitor therapy with quizartinib (167) or sorafenib (168-170). Baker et al. described three pediatric AML patients who partially responded to sunitinib treatment after developing sorafenibmediated TKD mutations D835H, D835Y, or F691L. However, two of these three patients had expansion of the D835Y population while on sunitinib, and this mutation was polyclonal, present on both ITD-positive and ITD-negative alleles (168). 
Interestingly, although many studies report that TKD mutations are not detected prior to FLT3 inhibitor therapy, emerging evidence suggests these TKD mutations may be present in a tiny sub-clone at pre-treatment, which is not easily detectable, but is selected for over time with FLT3 inhibitor therapy. Man et al. expanded LIC from pre-treatment patient samples in NOD/SCID mice. In these xenografts, D835Y-positive clones were expanded, which had only been detected in the paired post-sorafenib patient samples at relapse (169).

The patterns of TKD mutations and drug resistance are nonoverlapping, suggesting that combinations of FLT3 inhibitors may partially overcome the development of resistance (171). Type I FLT3 inhibitors, lestaurtinib and midostaurin, bind to the active formation of the FLT3 receptor, whereas type II inhibitors bind to the inactive formation (172). Also, not all acquired TKD mutations confer resistance in the same manner. Ba/F3 cells with $\mathrm{D} 835 \mathrm{H} / \mathrm{Y}$ demonstrate IL-3-independent growth and increased STAT5 phosphorylation, consistent with reports that D835 mutations are primary transforming events (173). Ba/F3 cells with FLT3-F691L are not transformed, suggesting that F691 mutations are secondary events and confer resistance by interfering with drug binding. Most FLT3 inhibitors make direct contact with residue F691 (166); although sunitinib does not, which could explain its conserved sensitivity in F691 mutants (168). In contrast, much evidence suggests that type II inhibitors quizartinib and sorafenib are inactive against D835 mutations, likely due to the mutant's stabilization of the FLT3 receptor in the active formation. Baker et al. showed that cells with FLT3-ITD-D835Y mutant were partially sensitive to midostaurin, which has type I inhibitor activity. However, the relatively lower potency of the first-generation type I inhibitors limit their efficacy as single agents. The next-generation FLT3 inhibitor crenolanib has shown promising efficacy against FLT3-ITD-D835Y AML samples, and is currently in a phase 2 clinical trial for adult AML (174). Taken together, these data argue for personalized selection and careful consideration of FLT3 inhibitor therapy in FLT3-ITD patients, and close monitoring for the emergence of TKD-mutant clones, which may be more susceptible to different FLT3 inhibitors.

Up-regulation of FLT3 receptor. Studies have shown increased expression of FLT3 itself in AML blasts during treatment with midostaurin (106) or lestaurtinib (113). It is not definitively known whether this observation represents a feedback loop that can act as a mechanism of resistance.

\section{CLONAL EVOLUTION OF THE LEUKEMIC STEM CELL}

Increasing evidence suggests that small populations of cancer stem cells can evade anti-neoplastic induced cytotoxicity $(175,176)$. Likewise in AML, genome-wide sequencing of paired diagnosticrelapsed samples reveal that multiple sub-clones are usually present at diagnosis, which have evolved from a "founding clone," synonymous with the LSC. At relapse, a dominant sub-clone emerges, either because the founding clone has gained additional mutations or a particular sub-clone has survived initial therapy (177). The latter mechanism of relapse is likely to be shaped by whatever remission-inducing therapy the patient has received. In vitro comparison of FLT3 inhibitor cytotoxicity in diagnostic and relapsed FLT3-ITD patient samples demonstrate that FLT3 inhibitor therapy is relatively less cytotoxic at diagnosis, despite adequate inhibition of FLT3 phosphorylation. This suggests that at diagnosis in FLT3-ITD AML, the dominant clone may not always be reliant on FLT3 signaling. In contrast, relapsed AML cells with a higher ITD allelic burden are more sensitive to FLT3 inhibitors, suggesting that an ITD dominant clone is more likely to emerge at relapse (178).

In order for a targeted therapy to eradicate disease, the target itself must be present in the cancer stem cell, and it remains controversial whether FLT3-ITD mutations are present in the LSC. FLT3-ITD mutations are present in $\mathrm{CD}_{3} 4^{+} 38^{-}$leukemic initiating cells (38) and confer an engraftment advantage over non-FLT3-ITD AML in a xenograft model (179), suggesting that ITD mutations are present in the LSC. However, ITD mutations occur as both early and late "hits" in patients. In some cases, ITD mutations were present at diagnosis and lost at relapse, and in other patients, ITD mutations were acquired at relapse, providing evidence the ITD mutation occurred in a sub-clone and not the LSC $(180,181)$. Determining at which stage the ITD mutation arises has significant clinical implications regarding the strategic use and timing of FLT3 inhibitor therapy in AML.

\section{FUTURE APPROACHES}

Careful treatment strategies are needed to increase the efficacy of targeted FLT3 therapy and decrease the development of resistance. The current approach to increasing efficacy has been to develop novel FLT3 inhibitors with increased potency and higher selectivity. However, as seen with quizartinib, these newer agents may increase the development of intrinsic resistance. Combining FLT3 inhibitors with chemotherapy improves responses, but does not preclude the development of resistance. When acquired mutations develop in BCR-ABL positive disease, the approach has been to switch to a different targeted agent. This approach could be taken in FLT3-ITD AML and would entail close monitoring for the development of TKD mutations while on FLT3 inhibitor therapy. Another approach could involve combining multiple FLT3 inhibitors that bind to different conformations of the receptor, in an attempt to prevent resistance. As discussed, some reports suggest that FLT3 inhibitors may be more effective in relapsed disease or in disease with a higher ITD allelic burden, and it might be prudent to reserve targeted therapy for those scenarios. Also, when FLT3 inhibitors are used in combination with chemotherapy, it may be possible to decrease the intensity of conventional chemotherapy drugs, and this might have the added benefit of lessening the FL surge demonstrated during more intensive chemotherapy. The development of a novel FL-inhibiting therapy would likely be synergistic with FLT3 inhibition. Perhaps, the most promising approach would be the dual inhibition of FLT3 and other pro-survival pathways, such as PI3K/AKT/mTOR, JAK/STAT5, or RAS/Raf/MEK/ERK inhibitors, and clinical trials investigating novel dual inhibitors (NCT02055781) or combining kinase inhibitors (NCT00819546) are underway ${ }^{1}$. Finally, combining FLT3 and CXCR4 inhibitors could overcome stromal protection of FLT3-activated leukemia cells and could be additive to any of the approaches above. 


\section{SUMMARY}

The identification of FLT3 aberrancies in high-risk subsets of leukemia patients was discovered two decades ago, and much has been learned about the biology, clinical implications, and targeting possibilities. It remains controversial whether FLT3-ITD is an initiating event in leukemogenesis, yet the striking development of intrinsic resistance with FLT3 inhibitor therapy supports its role as one of the most meaningful cooperating events in the development of human AML (177). Both adult and pediatric clinical trials continue to investigate different FLT3 inhibitors in combination with chemotherapy in patients with FLT3-mutant AML. Also, in MLL-r infant ALL, wild-type FLT3 overexpression portends an especially poor prognosis, and FLT3 inhibitor therapy in these patients is being investigated in a phase 3 clinical trial through the COG. In the meantime, resistance to FLT3-targeted therapy poses a significant challenge in the treatment of FLT3-activated leukemia patients.

\section{ACKNOWLEDGMENTS}

This work was supported by St. Baldrick's Foundation Fellowship Awards (Colleen E. Annesley), Leukemia and Lymphoma Society Scholar Award (Patrick Brown), and American Cancer Society Research Scholar Grant (Patrick Brown).

\section{REFERENCES}

1. Hunger SP, Lu X, Devidas M, Camitta BM, Gaynon PS, Winick NJ, et al. Improved survival for children and adolescents with acute lymphoblastic leukemia between 1990 and 2005: a report from the children's oncology group. J Clin Oncol (2012) 30(14):1663-9. doi:10.1200/JCO.2011.37.8018

2. Rubnitz JE. Childhood acute myeloid leukemia. Curr Treat Options Oncol (2008) 9(1):95-105. doi:10.1007/s11864-008-0059-z

3. Pui CH, Gajjar AJ, Kane JR, Qaddoumi IA, Pappo AS. Challenging issues in pediatric oncology. Nat Rev Clin Oncol (2011) 8(9):540-9. doi:10.1038/ nrclinonc.2011.95

4. Schultz KR, Bowman WP, Aledo A, Slayton WB, Sather H, Devidas M, et al. Improved early event-free survival with imatinib in Philadelphia chromosomepositive acute lymphoblastic leukemia: a children's oncology group study. J Clin Oncol (2009) 27(31):5175-81. doi:10.1200/JCO.2008.21.2514

5. Tallman MS, Andersen JW, Schiffer CA, Appelbaum FR, Feusner JH, Woods WG, et al. All-trans retinoic acid in acute promyelocytic leukemia: long-term outcome and prognostic factor analysis from the North American Intergroup protocol. Blood (2002) 100(13):4298-302. doi:10.1182/blood-2002-02-0632

6. Matthews W, Jordan CT, Wiegand GW, Pardoll D, Lemischka IR. A receptor tyrosine kinase specific to hematopoietic stem and progenitor cell-enriched populations. Cell (1991) 65(7):1143-52. doi:10.1016/0092-8674(91)90010-V

7. Rosnet O, Schiff C, Pebusque MJ, Marchetto S, Tonnelle C, Toiron Y, et al. Human FLT3/FLK2 gene: cDNA cloning and expression in hematopoietic cells. Blood (1993) 82(4):1110-9.

8. Small D, Levenstein M, Kim E, Carow C, Amin S, Rockwell P, et al. STK-1, the human homolog of Flk-2/Flt-3, is selectively expressed in CD34+ human bone marrow cells and is involved in the proliferation of early progenitor/stem cells. Proc Natl Acad Sci U S A (1994) 91(2):459-63. doi:10.1073/pnas.91.2.459

9. McKenna HJ. Role of hematopoietic growth factors/flt3 ligand in expansion and regulation of dendritic cells. Curr Opin Hematol (2001) 8(3):149-54. doi:10.1097/00062752-200105000-00004

10. deLapeyriere O, Naquet P, Planche J, Marchetto S, Rottapel R, Gambarelli D, et al. Expression of Flt3 tyrosine kinase receptor gene in mouse hematopoietic and nervous tissues. Differentiation (1995) 58(5):351-9. doi:10.1046/j.14320436.1995.5850351.x

11. MacKarehtschian K, Hardin JD, Moore KA, Boast S, Goff SP, Lemischka IR. Targeted disruption of the flk2/flt 3 gene leads to deficiencies in primitive hematopoietic progenitors. Immunity (1995) 3(1):147-61. doi:10.1016/10747613(95)90167-1
12. McKenna HJ, Stocking KL, Miller RE, Brasel K, De Smedt T, Maraskovsky E, et al. Mice lacking flt3 ligand have deficient hematopoiesis affecting hematopoietic progenitor cells, dendritic cells, and natural killer cells. Blood (2000) 95(11):3489-97.

13. Gotze KS, Ramirez M, Tabor K, Small D, Matthews W, Civin CI. Flt3high and Flt3low CD34+ progenitor cells isolated from human bone marrow are functionally distinct. Blood (1998) 91(6):1947-58.

14. Lyman SD, James L, Vanden Bos T, de Vries P, Brasel K, Gliniak B, et al. Molecular cloning of a ligand for the flt3/flk-2 tyrosine kinase receptor: a proliferative factor for primitive hematopoietic cells. Cell (1993) 75(6):1157-67. doi:10.1016/0092-8674(93)90325-K

15. Hannum C, Culpepper J, Campbell D, McClanahan T, Zurawski S, Bazan JF, et al. Ligand for FLT3/FLK2 receptor tyrosine kinase regulates growth of haematopoietic stem cells and is encoded by variant RNAs. Nature (1994) 368(6472):643-8. doi:10.1038/368643a0

16. Lyman SD, James L, Johnson L, Brasel K, de Vries P, Escobar SS, et al. Cloning of the human homologue of the murine flt3 ligand: a growth factor for early hematopoietic progenitor cells. Blood (1994) 83(10):2795-801.

17. Lisovsky M, Braun SE, Ge Y, Takahira H, Lu L, Savchenko VG, et al. Flt3ligand production by human bone marrow stromal cells. Leukemia (1996) 10(6):1012-8.

18. Lyman SD. Biology of flt3 ligand and receptor. Int J Hematol (1995) 62(2):63-73. doi:10.1016/0925-5710(95)00389-A

19. Rosnet O, Buhring HJ, deLapeyriere O, Beslu N, Lavagna C, Marchetto S, et al. Expression and signal transduction of the FLT3 tyrosine kinase receptor. Acta Haematol (1996) 95(3-4):218-23. doi:10.1159/000203881

20. Lavagna-Sevenier C, Marchetto S, Birnbaum D, Rosnet O. FLT3 signaling in hematopoietic cells involves CBL, SHC and an unknown P115 as prominent tyrosine-phosphorylated substrates. Leukemia (1998) 12(3):301-10. doi:10. 1038/sj.leu.2400921

21. Zhang S, Mantel C, Broxmeyer HE. Flt3 signaling involves tyrosylphosphorylation of SHP-2 and SHIP and their association with Grb2 and Shc in Baf3/Flt3 cells. J Leukoc Biol (1999) 65(3):372-80.

22. Zhang S, Broxmeyer HE. p 85 subunit of PI3 kinase does not bind to human Flt3 receptor, but associates with SHP2, SHIP, and a tyrosine-phosphorylated 100$\mathrm{kDa}$ protein in Flt3 ligand-stimulated hematopoietic cells. Biochem Biophys Res Commun (1999) 254(2):440-5. doi:10.1006/bbrc.1998.9959

23. Zhang S, Broxmeyer HE. Flt3 ligand induces tyrosine phosphorylation of gab1 and gab2 and their association with shp-2, grb2, and PI3 kinase. Biochem Biophys Res Commun (2000) 277(1):195-9. doi:10.1006/bbrc.2000.3662

24. Zhang S, Fukuda S, Lee Y, Hangoc G, Cooper S, Spolski R, et al. Essential role of signal transducer and activator of transcription (Stat)5a but not Stat5b for Flt3-dependent signaling. J Exp Med (2000) 192(5):719-28. doi:10.1084/jem.192.5.719

25. Birg F, Courcoul M, Rosnet O, Bardin F, Pebusque MJ, Marchetto S, et al. Expression of the FMS/KIT-like gene FLT3 in human acute leukemias of the myeloid and lymphoid lineages. Blood (1992) 80(10):2584-93.

26. Carow CE, Levenstein M, Kaufmann SH, Chen J, Amin S, Rockwell P, et al. Expression of the hematopoietic growth factor receptor FLT3 (STK-1/Flk2) in human leukemias. Blood (1996) 87(3):1089-96.

27. Meierhoff G, Dehmel U, Gruss HJ, Rosnet O, Birnbaum D, Quentmeier H, et al. Expression of FLT3 receptor and FLT3-ligand in human leukemia-lymphoma cell lines. Leukemia (1995) 9(8):1368-72.

28. Rosnet O, Buhring HJ, Marchetto S, Rappold I, Lavagna C, Sainty D, et al. Human FLT3/FLK2 receptor tyrosine kinase is expressed at the surface of normal and malignant hematopoietic cells. Leukemia (1996) 10(2):238-48.

29. Dehmel U, Zaborski M, Meierhoff G, Rosnet O, Birnbaum D, Ludwig WD, et al. Effects of FLT3 ligand on human leukemia cells. I. Proliferative response of myeloid leukemia cells. Leukemia (1996) 10(2):261-70.

30. Zheng R, Levis M, Piloto O, Brown P, Baldwin BR, Gorin NC, et al. FLT3 ligand causes autocrine signaling in acute myeloid leukemia cells. Blood (2004) 103(1):267-74. doi:10.1182/blood-2003-06-1969

31. Nakao M, Yokota S, Iwai T, Kaneko H, Horiike S, Kashima K, et al. Internal tandem duplication of the flt 3 gene found in acute myeloid leukemia. Leukemia (1996) 10(12):1911-8.

32. Kiyoi H, Towatari M, Yokota S, Hamaguchi M, Ohno R, Saito H, et al. Internal tandem duplication of the FLT3 gene is a novel modality of elongation mutation which causes constitutive activation of the product. Leukemia (1998) 12(9):1333-7. doi:10.1038/sj.leu.2401130 
33. Yokota S, Kiyoi H, Nakao M, Iwai T, Misawa S, Okuda T, et al. Internal tandem duplication of the FLT3 gene is preferentially seen in acute myeloid leukemia and myelodysplastic syndrome among various hematological malignancies. A study on a large series of patients and cell lines. Leukemia (1997) 11(10):1605-9. doi:10.1038/sj.leu.2400812

34. Kiyoi H, Ohno R, Ueda R, Saito H, Naoe T. Mechanism of constitutive activation of FLT3 with internal tandem duplication in the juxtamembrane domain. Oncogene (2002) 21(16):2555-63. doi:10.1038/sj.onc.1205332

35. Gilliland DG, Griffin JD. The roles of FLT3 in hematopoiesis and leukemia. Blood (2002) 100(5):1532-42. doi:10.1182/blood-2002-02-0492

36. Bonnet D, Dick JE. Human acute myeloid leukemia is organized as a hierarchy that originates from a primitive hematopoietic cell. Nat Med (1997) 3(7):730-7. doi:10.1038/nm0797-730

37. Kikushige Y, Yoshimoto G, Miyamoto T, Iino T, Mori Y, Iwasaki H, et al. Human Flt3 is expressed at the hematopoietic stem cell and the granulocyte/macrophage progenitor stages to maintain cell survival. J Immunol (2008) 180(11):7358-67. doi:10.4049/jimmunol.180.11.7358

38. Levis M, Murphy KM, Pham R, Kim KT, Stine A, Li L, et al. Internal tandem duplications of the FLT3 gene are present in leukemia stem cells. Blood (2005) 106(2):673-80. doi:10.1182/blood-2004-05-1902

39. Chu SH, Heiser D, Li L, Kaplan I, Collector M, Huso D, et al. FLT3-ITD knockin impairs hematopoietic stem cell quiescence/homeostasis, leading to myeloproliferative neoplasm. Cell Stem Cell (2012) 11(3):346-58. doi:10.1016/j.stem. 2012.05.027

40. Abu-Duhier FM, Goodeve AC, Wilson GA, Gari MA, Peake IR, Rees DC, et al. FLT3 internal tandem duplication mutations in adult acute myeloid leukaemia define a high-risk group. Br J Haematol (2000) 111(1):190-5. doi:10.1046/j.1365-2141.2000.02317.x

41. Kottaridis PD, Gale RE, Frew ME, Harrison G, Langabeer SE, Belton AA, et al. The presence of a FLT3 internal tandem duplication in patients with acute myeloid leukemia (AML) adds important prognostic information to cytogenetic risk group and response to the first cycle of chemotherapy: analysis of 854 patients from the United Kingdom Medical Research Council AML 10 and 12 trials. Blood (2001) 98(6):1752-9.

42. Thiede C, Steudel C, Mohr B, Schaich M, Schakel U, Platzbecker U, et al. Analysis of FLT3-activating mutations in 979 patients with acute myelogenous leukemia: association with FAB subtypes and identification of subgroups with poor prognosis. Blood (2002) 99(12):4326-35. doi:10.1182/blood.V99.12.4326

43. Levis M, Small D. FLT3: ITDoes matter in leukemia. Leukemia (2003) 17(9):1738-52. doi:10.1038/sj.leu.2403099

44. Kondo M, Horibe K, Takahashi Y, Matsumoto K, Fukuda M, Inaba J, et al. Prognostic value of internal tandem duplication of the FLT3 gene in childhood acute myelogenous leukemia. Med Pediatr Oncol (1999) 33(6):525-9. doi:10.1002/(SICI)1096-911X(199912)33:6<525::AID-MPO1>3.3.CO;2-\\#

45. Iwai T, Yokota S, Nakao M, Okamoto T, Taniwaki M, Onodera N, et al. Internal tandem duplication of the FLT3 gene and clinical evaluation in childhood acute myeloid leukemia. The Children's Cancer and Leukemia Study Group, Japan. Leukemia (1999) 13(1):38-43. doi:10.1038/sj.leu.2401241

46. Meshinchi S, Woods WG, Stirewalt DL, Sweetser DA, Buckley JD, Tjoa TK, et al. Prevalence and prognostic significance of Flt3 internal tandem duplication in pediatric acute myeloid leukemia. Blood (2001) 97(1):89-94. doi:10.1182/blood.V97.1.89

47. Pollard JA, Alonzo TA, Gerbing RB, Woods WG, Lange BJ, Sweetser DA, et al. FLT3 internal tandem duplication in CD34+/CD33- precursors predicts poor outcome in acute myeloid leukemia. Blood (2006) 108(8):2764-9. doi:10.1182/blood-2006-04-012260

48. Meshinchi S, Alonzo TA, Stirewalt DL, Zwaan M, Zimmerman M, Reinhardt D, et al. Clinical implications of FLT3 mutations in pediatric AML. Blood (2006) 108(12):3654-61. doi:10.1182/blood-2006-03-009233

49. Whitman SP, Archer KJ, Feng L, Baldus C, Becknell B, Carlson BD, et al. Absence of the wild-type allele predicts poor prognosis in adult de novo acute myeloid leukemia with normal cytogenetics and the internal tandem duplication of FLT3: a cancer and leukemia group B study. Cancer Res (2001) 61(19):7233-9.

50. Fitzgibbon J, Smith LL, Raghavan M, Smith ML, Debernardi S, Skoulakis $\mathrm{S}$, et al. Association between acquired uniparental disomy and homozygous gene mutation in acute myeloid leukemias. Cancer Res (2005) 65(20):9152-4. doi:10.1158/0008-5472.CAN-05-2017
51. Raghavan M, Smith LL, Lillington DM, Chaplin T, Kakkas I, Molloy G, et al. Segmental uniparental disomy is a commonly acquired genetic event in relapsed acute myeloid leukemia. Blood (2008) 112(3):814-21. doi:10.1182/ blood-2008-01-132431

52. Maclejewski JP, Mufti GJ. Whole genome scanning as a cytogenetic tool in hematologic malignancies. Blood (2008) 112(4):965-74. doi:10.1182/blood2008-02-130435

53. Wang Y, Armstrong SA. Genome-wide SNP analysis in cancer: leukemia shows the way. Cancer Cell (2007) 11(4):308-9. doi:10.1016/j.ccr.2007.03.017

54. Eklund EA. Genomic analysis of acute myeloid leukemia: potential for new prognostic indicators. Curr Opin Hematol (2010) 17(2):75-8. doi:10.1097/ MOH.0b013e3283366c43

55. O’Keefe C, McDevitt MA, MacIejewski JP. Copy neutral loss of heterozygosity: a novel chromosomal lesion in myeloid malignancies. Blood (2010) 115(14):2731-9. doi:10.1182/blood-2009-10-201848

56. Breitenbuecher F, Schnittger S, Grundler R, Markova B, Carius B, Brecht A, et al. Identification of a novel type of ITD mutations located in nonjuxtamembrane domains of the FLT3 tyrosine kinase receptor. Blood (2009) 113(17):4074-7. doi:10.1182/blood-2007-11-125476

57. Kayser S, Schlenk RF, Londono MC, Breitenbuecher F, Wittke K, Du J, et al. Insertion of FLT3 internal tandem duplication in the tyrosine kinase domain1 is associated with resistance to chemotherapy and inferior outcome. Blood (2009) 114(12):2386-92. doi:10.1182/blood-2009-03-209999

58. Stirewalt DL, Kopecky KJ, Meshinchi S, Engel JH, Pogosova-Agadjanyan EL, Linsley J, et al. Size of FLT3 internal tandem duplication has prognostic significance in patients with acute myeloid leukemia. Blood (2006) 107(9):3724-6. doi:10.1182/blood-2005-08-3453

59. Kusec R, Jaksic O, Ostojic S, Kardum-Skelin I, Vrhovac R, Jaksic B. More on prognostic significance of FLT3/ITD size in acute myeloid leukemia (AML). Blood (2006) 108(1):405-6. doi:10.1182/blood-2005-12-5128 author reply 406,

60. Kutny MA, Moser BK, Laumann K, Feusner JH, Gamis A, Gregory J, et al. FLT3 mutation status is a predictor of early death in pediatric acute promyelocytic leukemia: a report from the Children's Oncology Group. Pediatr Blood Cancer (2012) 59(4):662-7. doi:10.1002/pbc.24122

61. Marasca R, Maffei R, Zucchini P, Castelli I, Saviola A, Martinelli S, et al. Gene expression profiling of acute promyelocytic leukaemia identifies two subtypes mainly associated with flt3 mutational status. Leukemia (2006) 20(1):103-14. doi:10.1038/sj.leu.2404000

62. Hubbard SR. Juxtamembrane autoinhibition in receptor tyrosine kinases. Nat Rev Mol Cell Biol (2004) 5(6):464-71. doi:10.1038/nrm1399

63. Griffith J, Black J, Faerman C, Swenson L, Wynn M, Lu F, et al. The structural basis for autoinhibition of FLT3 by the juxtamembrane domain. Mol Cell (2004) 13(2):169-78. doi:10.1016/S1097-2765(03)00505-7

64. Mizuki M, Fenski R, Halfter H, Matsumura I, Schmidt R, Muller C, et al. Flt3 mutations from patients with acute myeloid leukemia induce transformation of 32D cells mediated by the Ras and STAT5 pathways. Blood (2000) 96(12):3907-14.

65. Hayakawa F, Towatari M, Kiyoi H, Tanimoto M, Kitamura T, Saito H, et al. Tandem-duplicated Flt3 constitutively activates STAT5 and MAP kinase and introduces autonomous cell growth in IL-3-dependent cell lines. Oncogene (2000) 19(5):624-31. doi:10.1038/sj.onc.1203354

66. Levis M, Allebach J, Tse KF, Zheng R, Baldwin BR, Smith BD, et al. A FLT3targeted tyrosine kinase inhibitor is cytotoxic to leukemia cells in vitro and in vivo. Blood (2002) 99(11):3885-91. doi:10.1182/blood.V99.11.3885

67. Wierenga AT, Schepers H, Moore MA, Vellenga E, Schuringa JJ. STAT5induced self-renewal and impaired myelopoiesis of human hematopoietic stem/progenitor cells involves down-modulation of C/EBPalpha. Blood (2006) 107(11):4326-33. doi:10.1182/blood-2005-11-4608

68. Benekli M, Baer MR, Baumann H, Wetzler M. Signal transducer and activator of transcription proteins in leukemias. Blood (2003) 101(8):2940-54. doi:10.1182/blood-2002-04-1204

69. Tse KF, Mukherjee G, Small D. Constitutive activation of FLT3 stimulates multiple intracellular signal transducers and results in transformation. Leukemia (2000) 14(10):1766-76. doi:10.1038/sj.leu.2401905

70. Quentmeier H, Reinhardt J, Zaborski M, Drexler HG. FLT3 mutations in acute myeloid leukemia cell lines. Leukemia (2003) 17(1):120-4. doi:10.1038/sj.leu. 2402740 
71. Choudhary C, Brandts C, Schwable J, Tickenbrock L, Sargin B, Ueker A, et al. Activation mechanisms of STAT5 by oncogenic Flt3-ITD. Blood (2007) 110(1):370-4. doi:10.1182/blood-2006-05-024018

72. Chen P, Levis M, Brown P, Kim KT, Allebach J, Small D. FLT3/ITD mutation signaling includes suppression of SHP-1. J Biol Chem (2005) 280(7):5361-9. doi:10.1074/jbc.M411974200

73. Zheng R, Friedman AD, Small D. Targeted inhibition of FLT3 overcomes the block to myeloid differentiation in $32 \mathrm{Dcl} 3$ cells caused by expression of FLT3/ITD mutations. Blood (2002) 100(12):4154-61. doi:10.1182/blood2002-03-0936

74. Zheng R, Friedman AD, Levis M, Li L, Weir EG, Small D. Internal tandem duplication mutation of FLT3 blocks myeloid differentiation through suppression of C/EBPalpha expression. Blood (2004) 103(5):1883-90. doi:10.1182/blood2003-06-1978

75. Kelly LM, Liu Q, Kutok JL, Williams IR, Boulton CL, Gilliland DG. FLT3 internal tandem duplication mutations associated with human acute myeloid leukemias induce myeloproliferative disease in a murine bone marrow transplant model. Blood (2002) 99(1):310-8. doi:10.1182/blood.V99.1.310

76. Li L, Piloto O, Nguyen HB, Greenberg K, Takamiya K, Racke F, et al. Knockin of an internal tandem duplication mutation into murine FLT3 confers myeloproliferative disease in a mouse model. Blood (2008) 111(7):3849-58. doi:10.1182/blood-2007-08-109942

77. Li L, Bailey E, Greenblatt S, Huso D, Small D. Loss of the wild-type allele contributes to myeloid expansion and disease aggressiveness in FLT3/ITD knockin mice. Blood (2011) 118(18):4935-45. doi:10.1182/blood-2011-01-328096

78. Stubbs MC, Kim YM, Krivtsov AV, Wright RD, Feng Z, Agarwal J, et al. MLLAF9 and FLT3 cooperation in acute myelogenous leukemia: development of a model for rapid therapeutic assessment. Leukemia (2008) 22(1):66-77. doi:10.1038/sj.leu. 2404951

79. Reckzeh K, Bereshchenko O, Mead A, Rehn M, Kharazi S, Jacobsen SE, et al. Molecular and cellular effects of oncogene cooperation in a genetically accurate AML mouse model. Leukemia (2012) 26(7):1527-36. doi:10.1038/leu.2012.37

80. Greenblatt S, Li L, Slape C, Nguyen B, Novak R, Duffield A, et al. Knock-in of a FLT3/ITD mutation cooperates with a NUP98-HOXD13 fusion to generate acute myeloid leukemia in a mouse model. Blood (2012) 119(12):2883-94. doi:10.1182/blood-2011-10-382283

81. Rau R, Magoon D, Greenblatt S, Li L, Annesley C, Duffield AS, et al. NPMc+ cooperates with Flt3/ITD mutations to cause acute leukemia recapitulating human disease. Exp Hematol (2014) 42(2):101.e-13.e. doi:10.1016/j.exphem. 2013.10.005

82. Kharazi S, Mead AJ, Mansour A, Hultquist A, Boiers C, Luc S, et al. Impact of gene dosage, loss of wild-type allele, and FLT3 ligand on Flt3-ITD-induced myeloproliferation. Blood (2011) 118(13):3613-21. doi:10.1182/blood-201006-289207

83. Zheng R, Bailey E, Nguyen B, Yang X, Piloto O, Levis M, et al. Further activation of FLT3 mutants by FLT3 ligand. Oncogene (2011) 30(38):4004-14. doi:10.1038/onc. 2011.110

84. Abu-Duhier FM, Goodeve AC, Wilson GA, Care RS, Peake IR, Reilly JT. Identification of novel FLT-3 Asp835 mutations in adult acute myeloid leukaemia. Br J Haematol (2001) 113(4):983-8. doi:10.1046/j.1365-2141.2001.02850.x

85. Yamamoto Y, Kiyoi H, Nakano Y, Suzuki R, Kodera Y, Miyawaki S, et al. Activating mutation of D835 within the activation loop of FLT3 in human hematologic malignancies. Blood (2001) 97(8):2434-9. doi:10.1182/blood.V97.8.2434

86. Boissan M, Feger F, Guillosson JJ, Arock M. c-Kit and c-kit mutations in mastocytosis and other hematological diseases. J Leukoc Biol (2000) 67(2):135-48.

87. Lacayo NJ, Meshinchi S, Kinnunen P, Yu R, Wang Y, Stuber CM, et al. Gene expression profiles at diagnosis in de novo childhood AML patients identify FLT3 mutations with good clinical outcomes. Blood (2004) 104(9):2646-54. doi:10.1182/blood-2003-12-4449

88. Moreno I, Martin G, Bolufer P, Barragan E, Rueda E, Roman J, et al. Incidence and prognostic value of FLT3 internal tandem duplication and D835 mutations in acute myeloid leukemia. Haematologica (2003) 88(1):19-24.

89. Armstrong SA, Kung AL, Mabon ME, Silverman LB, Stam RW, Den Boer ML, et al. Inhibition of FLT3 in MLL. Validation of a therapeutic target identified by gene expression based classification. Cancer Cell (2003) 3(2):173-83. doi:10.1016/S1535-6108(03)00003-5

90. Taketani T, Taki T, Sugita K, Furuichi Y, Ishii E, Hanada R, et al. FLT3 mutations in the activation loop of tyrosine kinase domain are frequently found in infant
ALL with MLL rearrangements and pediatric ALL with hyperdiploidy. Blood (2004) 103(3):1085-8. doi:10.1182/blood-2003-02-0418

91. Armstrong SA, Mabon ME, Silverman LB, Li A, Gribben JG, Fox EA, et al. FLT3 mutations in childhood acute lymphoblastic leukemia. Blood (2004) 103(9):3544-6. doi:10.1182/blood-2003-07-2441

92. Ishiko J, Mizuki M, Matsumura I, Shibayama H, Sugahara H, Scholz G, et al. Roles of tyrosine residues 845,892 and 922 in constitutive activation of murine FLT3 kinase domain mutant. Oncogene (2005) 24(55):8144-53.

93. Yamaguchi H, Hanawa H, Uchida N, Inamai M, Sawaguchi K, Mitamura Y, et al. Multistep pathogenesis of leukemia via the MLL-AF4 chimeric gene/Flt3 gene tyrosine kinase domain (TKD) mutation-related enhancement of S100A6 expression. Exp Hematol (2009) 37(6):701-14. doi:10.1016/j.exphem.2009.02. 007

94. Grundler R, Miething C, Thiede C, Peschel C, Duyster J. FLT3-ITD and tyrosine kinase domain mutants induce 2 distinct phenotypes in a murine bone marrow transplantation model. Blood (2005) 105(12):4792-9. doi:10.1182/blood2004-11-4430

95. Bailey E, Li L, Duffield AS, Ma HS, Huso DL, Small D. FLT3/D835Y mutation knock-in mice display less aggressive disease compared with FLT3/internal tandem duplication (ITD) mice. Proc Natl Acad Sci U S A (2013) 110(52):21113-8. doi:10.1073/pnas.1310559110

96. Armstrong SA, Staunton JE, Silverman LB, Pieters R, den Boer ML, Minden $\mathrm{MD}$, et al. MLL translocations specify a distinct gene expression profile that distinguishes a unique leukemia. Nat Genet (2002) 30(1):41-7. doi:10.1038/ ng765

97. Brown P, Levis M, Shurtleff S, Campana D, Downing J, Small D. FLT3 inhibition selectively kills childhood acute lymphoblastic leukemia cells with high levels of FLT3 expression. Blood (2005) 105(2):812-20. doi:10.1182/blood-2004-062498

98. Stam RW, den Boer ML, Schneider P, Nollau P, Horstmann M, Beverloo $\mathrm{HB}$, et al. Targeting FLT3 in primary MLL-gene-rearranged infant acute lymphoblastic leukemia. Blood (2005) 106(7):2484-90. doi:10.1182/blood-200409-3667

99. Chillon MC, Gomez-Casares MT, Lopez-Jorge CE, Rodriguez-Medina C, Molines A, Sarasquete ME, et al. Prognostic significance of FLT3 mutational status and expression levels in MLL-AF4+ and MLL-germline acute lymphoblastic leukemia. Leukemia (2012) 26(11):2360-6. doi:10.1038/leu.2012. 161

100. Stam RW, Schneider P, de Lorenzo P, Valsecchi MG, den Boer ML, Pieters R. Prognostic significance of high-level FLT3 expression in MLL-rearranged infant acute lymphoblastic leukemia. Blood (2007) 110(7):2774-5. doi:10. 1182/blood-2007-05-091934

101. Yeoh EJ, Ross ME, Shurtleff SA, Williams WK, Patel D, Mahfouz R, et al. Classification, subtype discovery, and prediction of outcome in pediatric acute lymphoblastic leukemia by gene expression profiling. Cancer Cell (2002) 1(2):133-43. doi:10.1016/S1535-6108(02)00032-6

102. Hawley TS, Fong AZ, Griesser H, Lyman SD, Hawley RG. Leukemic predisposition of mice transplanted with gene-modified hematopoietic precursors expressing flt3 ligand. Blood (1998) 92(6):2003-11.

103. Tse KF, Novelli E, Civin CI, Bohmer FD, Small D. Inhibition of FLT3mediated transformation by use of a tyrosine kinase inhibitor. Leukemia (2001) 15(7):1001-10. doi:10.1038/sj.leu.2402199

104. Levis M, Tse KF, Smith BD, Garrett E, Small DA. FLT3 tyrosine kinase inhibitor is selectively cytotoxic to acute myeloid leukemia blasts harboring FLT3 internal tandem duplication mutations. Blood (2001) 98(3):885-7. doi:10.1182/blood.V98.3.885

105. Brown P, Meshinchi S, Levis M, Alonzo TA, Gerbing R, Lange B, et al. Pediatric AML primary samples with FLT3/ITD mutations are preferentially killed by FLT3 inhibition. Blood (2004) 104(6):1841-9. doi:10.1182/blood-2004-031034

106. Weisberg E, Boulton C, Kelly LM, Manley P, Fabbro D, Meyer T, et al. Inhibition of mutant FLT3 receptors in leukemia cells by the small molecule tyrosine kinase inhibitor PKC412. Cancer Cell (2002) 1(5):433-43. doi:10.1016/S1535-6108(02)00069-7

107. Levis M, Pham R, Smith BD, Small D. In vitro studies of a FLT3 inhibitor combined with chemotherapy: sequence of administration is important to achieve synergistic cytotoxic effects. Blood (2004) 104(4):1145-50. doi:10.1182/blood2004-01-0388 
108. Brown P, Levis M, McIntyre E, Griesemer M, Small D. Combinations of the FLT3 inhibitor CEP-701 and chemotherapy synergistically kill infant and childhood MLL-rearranged ALL cells in a sequence-dependent manner. Leukemia (2006) 20(8):1368-76. doi:10.1038/sj.leu.2404277

109. Levis M, Brown P, Smith BD, Stine A, Pham R, Stone R, et al. Plasma inhibitory activity (PIA): a pharmacodynamic assay reveals insights into the basis for cytotoxic response to FLT3 inhibitors. Blood (2006) 108(10):3477-83. doi:10.1182/blood-2006-04-015743

110. Smith BD, Levis M, Beran M, Giles F, Kantarjian H, Berg K, et al. Singleagent CEP-701, a novel FLT3 inhibitor, shows biologic and clinical activity in patients with relapsed or refractory acute myeloid leukemia. Blood (2004) 103(10):3669-76. doi:10.1182/blood-2003-11-3775

111. Inaba H, Rubnitz JE, Coustan-Smith E, Li L, Furmanski BD, Mascara GP, et al. Phase I pharmacokinetic and pharmacodynamic study of the multikinase inhibitor sorafenib in combination with clofarabine and cytarabine in pediatric relapsed/refractory leukemia. J Clin Oncol (2011) 29(24):3293-300. doi:10.1200/JCO.2011.34.7427

112. Widemann BC, Kim A, Fox E, Baruchel S, Adamson PC, Ingle AM, et al. A phase I trial and pharmacokinetic study of sorafenib in children with refractory solid tumors or leukemias: a Children's Oncology Group Phase I Consortium report. Clin Cancer Res (2012) 18(21):6011-22. doi:10.1158/1078-0432.CCR-11-3284

113. Knapper S, Burnett AK, Littlewood T, Kell WJ, Agrawal S, Chopra R, et al. A phase 2 trial of the FLT3 inhibitor lestaurtinib (CEP701) as first-line treatment for older patients with acute myeloid leukemia not considered fit for intensive chemotherapy. Blood (2006) 108(10):3262-70. doi:10.1182/blood-200604-015560

114. Levis M, Ravandi F, Wang ES, Baer MR, Perl A, Coutre S, et al. Results from a randomized trial of salvage chemotherapy followed by lestaurtinib for patients with FLT3 mutant AML in first relapse. Blood (2011) 117(12):3294-301. doi:10.1182/blood-2010-08-301796

115. Stone RM, DeAngelo DJ, Klimek V, Galinsky I, Estey E, Nimer SD, et al. Patients with acute myeloid leukemia and an activating mutation in FLT3 respond to a small-molecule FLT3 tyrosine kinase inhibitor, PKC412. Blood (2005) 105(1):54-60. doi:10.1182/blood-2004-03-0891

116. Fischer T, Stone RM, Deangelo DJ, Galinsky I, Estey E, Lanza C, et al. Phase IIB trial of oral Midostaurin (PKC412), the FMS-like tyrosine kinase 3 receptor (FLT3) and multi-targeted kinase inhibitor, in patients with acute myeloid leukemia and high-risk myelodysplastic syndrome with either wild-type or mutated FLT3. J Clin Oncol (2010) 28(28):4339-45. doi:10.1200/JCO.2010.28. 9678

117. Stone RM, Fischer T, Paquette R, Schiller G, Schiffer CA, Ehninger G, et al. Phase IB study of the FLT3 kinase inhibitor midostaurin with chemotherapy in younger newly diagnosed adult patients with acute myeloid leukemia. Leukemia (2012) 26(9):2061-8. doi:10.1038/leu.2012.115

118. Zarrinkar PP, Gunawardane RN, Cramer MD, Gardner MF, Brigham D, Belli $\mathrm{B}$, et al. AC220 is a uniquely potent and selective inhibitor of FLT3 for the treatment of acute myeloid leukemia (AML). Blood (2009) 114(14):2984-92. doi:10.1182/blood-2009-05-222034

119. Kampa-Schittenhelm KM, Heinrich MC, Akmut F, Dohner H, Dohner K, Schittenhelm MM. Quizartinib (AC220) is a potent second generation class III tyrosine kinase inhibitor that displays a distinct inhibition profile against mutantFLT3, -PDGFRA and -KIT isoforms. Mol Cancer (2013) 12:19. doi:10.1186/ 1476-4598-12-19

120. Cortes JE, Kantarjian H, Foran JM, Ghirdaladze D, Zodelava M, Borthakur G, et al. Phase I study of quizartinib administered daily to patients with relapsed or refractory acute myeloid leukemia irrespective of FMS-like tyrosine kinase 3-internal tandem duplication status. J Clin Oncol (2013) 31(29):3681-7. doi:10.1200/JCO.2013.48.8783

121. Cortes JE, Perl AE, Dombret H, Kayser S, Steffen B, Rousselot P, et al. Final Results of a phase 2 open-label, monotherapy efficacy and safety study of quizartinib (AC220) in patients $>=60$ years of age with FLT3 ITD positive or negative relapsed/refractory acute myeloid leukemia. ASH Annu Meet Abstr (2012) 120(21):48.

122. Levis MJ, Perl AE, Dombret H, Dohner H, Steffen B, Rousselot P, et al. Final results of a phase 2 open-label, monotherapy efficacy and safety study of quizartinib (AC220) in patients with FLT3-ITD positive or negative relapsed/refractory acute myeloid leukemia after second-line chemotherapy or hematopoietic stem cell transplantation. ASH Annu Meet Abstr (2012) 120(21):673.
123. Malvar J, Cassar J, Eckroth E, Sposto R, Gaynon P, Dubois S, et al. A phase I study of AC220 (quizartinib) in combination with cytarabine and etoposide in relapsed/refractory childhood ALL and AML: a therapeutic advances in childhood leukemia \& lymphoma (TACL) study. Blood (2013) 122(21):624-624.

124. Zhang W, Konopleva M, Shi YX, McQueen T, Harris D, Ling X, et al. Mutant FLT3: a direct target of sorafenib in acute myelogenous leukemia. J Natl Cancer Inst (2008) 100(3):184-98. doi:10.1093/jnci/djm328

125. Crump M, Hedley D, Kamel-Reid S, Leber B, Wells R, Brandwein J, et al. A randomized phase I clinical and biologic study of two schedules of sorafenib in patients with myelodysplastic syndrome or acute myeloid leukemia: a NCIC (National Cancer Institute of Canada) Clinical Trials Group Study. Leuk Lymphoma (2010) 51(2):252-60. doi:10.3109/10428190903585286

126. Pratz KW, Cortes J, Roboz GJ, Rao N, Arowojolu O, Stine A, et al. A pharmacodynamic study of the FLT3 inhibitor KW-2449 yields insight into the basis for clinical response. Blood (2009) 113(17):3938-46. doi:10.1182/blood-200809- 177030

127. Ravandi F, Cortes JE, Jones D, Faderl S, Garcia-Manero G, Konopleva MY, et al. Phase I/II study of combination therapy with sorafenib, idarubicin, and cytarabine in younger patients with acute myeloid leukemia. J Clin Oncol (2010) 28(11):1856-62. doi:10.1200/JCO.2009.25.4888

128. Serve H, Wagner R, Sauerland C, Brunnberg U, Krug U, Schaich M, et al. Sorafenib in combination with standard induction and consolidation therapy in elderly AML patients: results from a randomized, placebo-controlled phase II trial. ASH Annu Meet Abstr (2010) 116(21):333.

129. Watt TC, Cooper T. Sorafenib as treatment for relapsed or refractory pediatric acute myelogenous leukemia. Pediatr Blood Cancer (2012) 59(4):756-7. doi:10.1002/pbc.23394

130. Mori M, Kaneko N, Ueno Y, Tanaka R, Cho K, Saito R, et al. ASP2215, a novel FLT3/AXL inhibitor: preclinical evaluation in acute myeloid leukemia (AML). ASCO Meet Abstr (2014) 32(15 Suppl):7070.

131. Ueno Y, Kaneko N, Saito R, Kondoh Y, Shimada I, Mori M, et al. ASP2215, a novel FLT3/AXL inhibitor: preclinical evaluation in combination with cytarabine and anthracycline in acute myeloid leukemia (AML). ASCO Meet Abstr (2014) 32(15 Suppl):7071.

132. Schlenk RF, Dohner K, Krauter J, Frohling S, Corbacioglu A, Bullinger L, et al. Mutations and treatment outcome in cytogenetically normal acute myeloid leukemia. N Engl J Med (2008) 358(18):1909-18. doi:10.1056/NEJMoa074306

133. DeZern AE, Sung A, Kim S, Smith BD, Karp JE, Gore SD, et al. Role of allogeneic transplantation for FLT3/ITD acute myeloid leukemia: outcomes from 133 consecutive newly diagnosed patients from a single institution. Biol Blood Marrow Transplant (2011) 17(9):1404-9. doi:10.1016/j.bbmt.2011.02.003

134. Koh KN, Park M, Kim BE, Bae KW, Im HJ, Seo JJ. Favorable outcomes after allogeneic hematopoietic stem cell transplantation in children with high-risk or advanced acute myeloid leukemia. J Pediatr Hematol Oncol (2011) 33(4):281-8. doi:10.1097/MPH.0b013e318203e279

135. Burke MJ, Wagner JE, Cao Q, Ustun C, Verneris MR. Allogeneic hematopoietic cell transplantation in first remission abrogates poor outcomes associated with high-risk pediatric acute myeloid leukemia. Biol Blood Marrow Transplant (2013) 19(7):1021-5. doi:10.1016/j.bbmt.2013.04.001

136. Metzelder S, Wang Y, Wollmer E, Wanzel M, Teichler S, Chaturvedi A, et al. Compassionate use of sorafenib in FLT3-ITD-positive acute myeloid leukemia: sustained regression before and after allogeneic stem cell transplantation. Blood (2009) 113(26):6567-71. doi:10.1182/blood-2009-03-208298

137. Winkler J, Rech D, Kallert S, Rech J, Meidenbauer N, Roesler W, et al. Sorafenib induces sustained molecular remission in FLT3-ITD positive AML with relapse after second allogeneic stem cell transplantation without exacerbation of acute GVHD: a case report. Leuk Res (2010) 34(10):e270-2. doi:10.1016/j.leukres.2010.04.011

138. Sharma M, Ravandi F, Bayraktar UD, Chiattone A, Bashir Q, Giralt S, et al. Treatment of FLT3-ITD-positive acute myeloid leukemia relapsing after allogeneic stem cell transplantation with sorafenib. Biol Blood Marrow Transplant (2011) 17(12):1874-7. doi:10.1016/j.bbmt.2011.07.011

139. Metzelder SK, Schroeder T, Finck A, Scholl S, Fey M, Gotze K, et al. High activity of sorafenib in FLT3-ITD-positive acute myeloid leukemia synergizes with alloimmune effects to induce sustained responses. Leukemia (2012) 26(11):2353-9. doi:10.1038/leu.2012.105

140. Grunwald MR, Levis MJ. FLT3 inhibitors for acute myeloid leukemia: a review of their efficacy and mechanisms of resistance. Int J Hematol (2013) 97(6):683-94. doi:10.1007/s12185-013-1334-8 
141. Yin OQ, Wang Y, Schran H. A mechanism-based population pharmacokinetic model for characterizing time-dependent pharmacokinetics of midostaurin and its metabolites in human subjects. Clin Pharmacokinet (2008) 47(12):807-16. doi:10.2165/0003088-200847120-00005

142. Knapper S, Burnett AK, Hills RK, Small D, Levis M. Lestaurtinib FLT3 Inhibitory Activity Is Modulated by Concomitant Azole Therapy and May Influence Relapse Risk. ASH Annu Meet Abstr (2009) 114(22):789.

143. Minami Y, Yamamoto K, Kiyoi H, Ueda R, Saito H, Naoe T. Different antiapoptotic pathways between wild-type and mutated FLT3: insights into therapeutic targets in leukemia. Blood (2003) 102(8):2969-75. doi:10.1182/blood-200212-3813

144. Kohl TM, Hellinger C, Ahmed F, Buske C, Hiddemann W, Bohlander SK, et al. BH3 mimetic ABT-737 neutralizes resistance to FLT3 inhibitor treatment mediated by FLT3-independent expression of BCL2 in primary AML blasts. Leukemia (2007) 21(8):1763-72. doi:10.1038/sj.leu.2404776

145. Stolzel F, Steudel C, Oelschlagel U, Mohr B, Koch S, Ehninger G, et al. Mechanisms of resistance against PKC412 in resistant FLT3-ITD positive human acute myeloid leukemia cells. Ann Hematol (2010) 89(7):653-62. doi:10.1007/s00277-009-0889-1

146. Knapper S, Mills KI, Gilkes AF, Austin SJ, Walsh V, Burnett AK. The effects of lestaurtinib (CEP701) and PKC412 on primary AML blasts: the induction of cytotoxicity varies with dependence on FLT3 signaling in both FLT3mutated and wild-type cases. Blood (2006) 108(10):3494-503. doi:10.1182/ blood-2006-04-015487

147. Piloto O, Wright M, Brown P, Kim KT, Levis M, Small D. Prolonged exposure to FLT3 inhibitors leads to resistance via activation of parallel signaling pathways. Blood (2007) 109(4):1643-52. doi:10.1182/blood-2006-05-023804

148. Sato T, Yang X, Knapper S, White P, Smith BD, Galkin S, et al. FLT3 ligand impedes the efficacy of FLT3 inhibitors in vitro and in vivo. Blood (2011) 117(12):3286-93. doi:10.1182/blood-2010-01-266742

149. Zhou J, Bi C, Janakakumara JV, Liu SC, Chng WJ, Tay KG, et al. Enhanced activation of STAT pathways and overexpression of survivin confer resistance to FLT3 inhibitors and could be therapeutic targets in AML. Blood (2009) 113(17):4052-62. doi:10.1182/blood-2008-05-156422

150. Wilson A, Trumpp A. Bone-marrow haematopoietic-stem-cell niches. Nat Rev Immunol (2006) 6(2):93-106. doi:10.1038/nri1779

151. Mony U, Jawad M, Seedhouse C, Russell N, Pallis M. Resistance to FLT3 inhibition in an in vitro model of primary AML cells with a stem cell phenotype in a defined microenvironment. Leukemia (2008) 22(7):1395-401. doi:10.1038/leu.2008.125

152. Parmar A, Marz S, Rushton S, Holzwarth C, Lind K, Kayser S, et al. Stromal niche cells protect early leukemic FLT3-ITD+ progenitor cells against first-generation FLT3 tyrosine kinase inhibitors. Cancer Res (2011) 71(13):4696-706. doi:10.1158/0008-5472.CAN-10-4136

153. Burger JA, Tsukada N, Burger M, Zvaifler NJ, Dell'Aquila M, Kipps TJ. Bloodderived nurse-like cells protect chronic lymphocytic leukemia B cells from spontaneous apoptosis through stromal cell-derived factor-1. Blood (2000) 96(8):2655-63.

154. Tavor S, Petit I, Porozov S, Avigdor A, Dar A, Leider-Trejo L, et al. CXCR4 regulates migration and development of human acute myelogenous leukemia stem cells in transplanted NOD/SCID mice. Cancer Res (2004) 64(8):2817-24. doi:10.1158/0008-5472.CAN-03-3693

155. Fukuda S, Broxmeyer HE, Pelus LM. Flt3 ligand and the Flt3 receptor regulate hematopoietic cell migration by modulating the SDFlalpha(CXCL12)/CXCR4 axis. Blood (2005) 105(8):3117-26. doi:10.1182/ blood-2004-04-1440

156. Rombouts EJ, Pavic B, Lowenberg B, Ploemacher RE. Relation between CXCR-4 expression, Flt3 mutations, and unfavorable prognosis of adult acute myeloid leukemia. Blood (2004) 104(2):550-7. doi:10.1182/blood-200402-0566

157. Zeng Z, Shi YX, Samudio IJ, Wang RY, Ling X, Frolova O, et al. Targeting the leukemia microenvironment by CXCR4 inhibition overcomes resistance to kinase inhibitors and chemotherapy in AML. Blood (2009) 113(24):6215-24. doi:10.1182/blood-2008-05-158311

158. Nervi B, Ramirez P, Rettig MP, Uy GL, Holt MS, Ritchey JK, et al. Chemosensitization of acute myeloid leukemia (AML) following mobilization by the CXCR4 antagonist AMD3100. Blood (2009) 113(24):6206-14. doi:10.1182/ blood-2008-06-162123
159. Sison EA, Rau RE, McIntyre E, Li L, Small D, Brown P. MLL-rearranged acute lymphoblastic leukaemia stem cell interactions with bone marrow stroma promote survival and therapeutic resistance that can be overcome with CXCR4 antagonism. Br J Haematol (2013) 160(6):785-97. doi:10.1111/bjh.12205

160. Gorre ME, Mohammed M, Ellwood K, Hsu N, Paquette R, Rao PN, et al. Clinical resistance to STI-571 cancer therapy caused by BCR-ABL gene mutation or amplification. Science (2001) 293(5531):876-80. doi:10.1126/science.1062538

161. Smith CC, Wang Q, Chin CS, Salerno S, Damon LE, Levis MJ, et al. Validation of ITD mutations in FLT3 as a therapeutic target in human acute myeloid leukaemia. Nature (2012) 485(7397):260-3. doi:10.1038/nature11016

162. Cools J, Mentens N, Furet P, Fabbro D, Clark JJ, Griffin JD, et al. Prediction of resistance to small molecule FLT3 inhibitors: implications for molecularly targeted therapy of acute leukemia. Cancer Res (2004) 64(18):6385-9. doi:10.1158/0008-5472.CAN-04-2148

163. Bagrintseva K, Schwab R, Kohl TM, Schnittger S, Eichenlaub S, Ellwart JW, et al Mutations in the tyrosine kinase domain of FLT3 define a new molecular mechanism of acquired drug resistance to PTK inhibitors in FLT3-ITD-transformed hematopoietic cells. Blood (2004) 103(6):2266-75. doi:10.1182/blood-200305-1653

164. Heidel F, Solem FK, Breitenbuecher F, Lipka DB, Kasper S, Thiede MH, et al. Clinical resistance to the kinase inhibitor PKC412 in acute myeloid leukemia by mutation of Asn-676 in the FLT3 tyrosine kinase domain. Blood (2006) 107(1):293-300. doi:10.1182/blood-2005-06-2469

165. von Bubnoff N, Rummelt C, Menzel H, Sigl M, Peschel C, Duyster J. Identification of a secondary FLT3/A848P mutation in a patient with FLT3-ITD-positive blast phase CMML and response to sunitinib and sorafenib. Leukemia (2010) 24(8):1523-5. doi:10.1038/leu.2010.122

166. Williams AB, Nguyen B, Li L, Brown P, Levis M, Leahy D, et al. Mutations of FLT3/ITD confer resistance to multiple tyrosine kinase inhibitors. Leukemia (2013) 27(1):48-55. doi:10.1038/leu.2012.191

167. Albers C, Leischner H, Verbeek M, Yu C, Illert AL, Peschel C, et al. The secondary FLT3-ITD F691L mutation induces resistance to AC220 in FLT3-ITD+ AML but retains in vitro sensitivity to PKC412 and Sunitinib. Leukemia (2013) 27(6):1416-8. doi:10.1038/leu.2013.14

168. Baker SD, Zimmerman EI, Wang YD, Orwick S, Zatechka DS, Buaboonnam J, et al. Emergence of polyclonal FLT3 tyrosine kinase domain mutations during sequential therapy with sorafenib and sunitinib in FLT3-ITDpositive acute myeloid leukemia. Clin Cancer Res (2013) 19(20):5758-68. doi:10.1158/1078-0432.CCR-13-1323

169. Man CH, Fung TK, Ho C, Han HH, Chow HC, Ma AC, et al. Sorafenib treatment of FLT3-ITD $(+)$ acute myeloid leukemia: favorable initial outcome and mechanisms of subsequent nonresponsiveness associated with the emergence of a D835 mutation. Blood (2012) 119(22):5133-43. doi:10.1182/blood-201106-363960

170. Zhang W, Konopleva M, Jacamo RO, Borthakur G, Chen W, Cortes JE, et al. Acquired point mutations of TKD are responsible for sorafenib resistance in FLT3-ITD mutant AML. ASH Annu Meet Abstr (2011) 118(21):3505. doi:10.1158/1078-0432.CCR-13-2052

171. von Bubnoff N, Engh RA, Aberg E, Sanger J, Peschel C, Duyster J. FMS-like tyrosine kinase 3-internal tandem duplication tyrosine kinase inhibitors display a nonoverlapping profile of resistance mutations in vitro. Cancer Res (2009) 69(7):3032-41. doi:10.1158/0008-5472.CAN-08-2923

172. Weisberg E, Roesel J, Furet P, Bold G, Imbach P, Florsheimer A, et al. Antileukemic effects of novel first- and second-generation FLT3 inhibitors: structure-affinity comparison. Genes Cancer (2010) 1(10):1021-32. doi:10. $1177 / 1947601910396505$

173. Whitman SP, Ruppert AS, Radmacher MD, Mrozek K, Paschka P, Langer C, et al. FLT3 D835/I836 mutations are associated with poor disease-free survival and a distinct gene-expression signature among younger adults with de novo cytogenetically normal acute myeloid leukemia lacking FLT3 internal tandem duplications. Blood (2008) 111(3):1552-9. doi:10.1182/blood-2007-08-107946

174. Galanis A, Ma H, Rajkhowa T, Ramachandran A, Small D, Cortes J, et al. Crenolanib is a potent inhibitor of FLT3 with activity against resistanceconferring point mutants. Blood (2014) 123(1):94-100. doi:10.1182/blood2013-10-529313

175. Jordan CT, Guzman ML. Mechanisms controlling pathogenesis and survival of leukemic stem cells. Oncogene (2004) 23(43):7178-87. doi:10.1038/sj.onc. 1207935 
176. Stubbs MC, Armstrong SA. Therapeutic implications of leukemia stem cell development. Clin Cancer Res (2007) 13(12):3439-42. doi:10.1158/1078-0432. CCR-06-3090

177. Welch JS, Ley TJ, Link DC, Miller CA, Larson DE, Koboldt DC, et al. The origin and evolution of mutations in acute myeloid leukemia. Cell (2012) 150(2):264-78. doi:10.1016/j.cell.2012.06.023

178. Pratz KW, Sato T, Murphy KM, Stine A, Rajkhowa T, Levis M. FLT3-mutant allelic burden and clinical status are predictive of response to FLT3 inhibitors in AML. Blood (2010) 115(7):1425-32. doi:10.1182/blood-2009-09-242859

179. Lumkul R, Gorin NC, Malehorn MT, Hoehn GT, Zheng R, Baldwin B, et al. Human AML cells in NOD/SCID mice: engraftment potential and gene expression. Leukemia (2002) 16(9):1818-26. doi:10.1038/sj.leu.2402632

180. Kottaridis PD, Gale RE, Langabeer SE, Frew ME, Bowen DT, Linch DC. Studies of FLT3 mutations in paired presentation and relapse samples from patients with acute myeloid leukemia: implications for the role of FLT3 mutations in leukemogenesis, minimal residual disease detection, and possible therapy with FLT3 inhibitors. Blood (2002) 100(7):2393-8. doi:10.1182/blood-200202-0420

181. Shih LY, Huang CF, Wu JH, Lin TL, Dunn P, Wang PN, et al. Internal tandem duplication of FLT3 in relapsed acute myeloid leukemia: a comparative analysis of bone marrow samples from 108 adult patients at diagnosis and relapse. Blood (2002) 100(7):2387-92. doi:10.1182/blood-2002-01-0195

Conflict of Interest Statement: The authors declare that the research was conducted in the absence of any commercial or financial relationships that could be construed as a potential conflict of interest.

Received: 18 July 2014; accepted: 08 September 2014; published online: 23 September 2014.

Citation: Annesley CE and Brown P (2014) The biology and targeting of FLT3 in pediatric leukemia. Front. Oncol. 4:263. doi: 10.3389/fonc.2014.00263

This article was submitted to Pediatric Oncology, a section of the journal Frontiers in Oncology.

Copyright $\left({ }_{0} 2014\right.$ Annesley and Brown. This is an open-access article distributed under the terms of the Creative Commons Attribution License (CC BY). The use, distribution or reproduction in other forums is permitted, provided the original author(s) or licensor are credited and that the original publication in this journal is cited, in accordance with accepted academic practice. No use, distribution or reproduction is permitted which does not comply with these terms. 